\title{
Direct ecosystem fluxes of volatile organic compounds from oil palms in South-East Asia
}

\author{
P. K. Misztal ${ }^{1,2, *}$, E. Nemitz ${ }^{1}$, B. Langford ${ }^{1}$, C. F. Di Marco ${ }^{1}$, G. J. Phillips ${ }^{1,{ }^{* *}}$, C. N. Hewitt ${ }^{3}$, A. R. MacKenzie ${ }^{3}$, \\ S. M. Owen ${ }^{1}$, D. Fowler ${ }^{1}$, M. R. Heal ${ }^{2}$, and J. N. Cape ${ }^{1}$ \\ ${ }^{1}$ Centre for Ecology \& Hydrology, Penicuik, EH26 0QB, UK \\ ${ }^{2}$ School of Chemistry, University of Edinburgh, EH9 3JJ, UK \\ ${ }^{3}$ Lancaster Environment Centre, Lancaster University, LA1 4YQ, UK \\ * currently at: Department of Environmental Science, Policy, and Management, University of California, Berkeley, CA, USA \\ ** now at: Max-Planck-Institut für Chemie, Division of Atmospheric Chemistry, Postfach 3060, 55020 Mainz, Germany
}

Received: 27 March 2011 - Published in Atmos. Chem. Phys. Discuss.: 26 April 2011

Revised: 6 August 2011 - Accepted: 24 August 2011 - Published: 2 September 2011

\begin{abstract}
This paper reports the first direct eddy covariance fluxes of reactive biogenic volatile organic compounds (BVOCs) from oil palms to the atmosphere using protontransfer-reaction mass spectrometry (PTR-MS), measured at a plantation in Malaysian Borneo. At midday, net isoprene flux constituted the largest fraction $(84 \%)$ of all emitted BVOCs measured, at up to $30 \mathrm{mg} \mathrm{m}^{-2} \mathrm{~h}^{-1}$ over 12 days. By contrast, the sum of its oxidation products methyl vinyl ketone (MVK) and methacrolein (MACR) exhibited clear deposition of $1 \mathrm{mg} \mathrm{m}^{-2} \mathrm{~h}^{-1}$, with a small average canopy resistance of $230 \mathrm{~s} \mathrm{~m}^{-1}$. Approximately $15 \%$ of the resolved BVOC flux from oil palm trees could be attributed to floral emissions, which are thought to be the largest reported biogenic source of estragole and possibly also toluene. Although on average the midday volume mixing ratio of estragole exceeded that of toluene by almost a factor of two, the corresponding fluxes of these two compounds were nearly the same, amounting to 0.81 and $0.76 \mathrm{mg} \mathrm{m}^{-2} \mathrm{~h}^{-1}$, respectively. By fitting the canopy temperature and PAR response of the MEGAN emissions algorithm for isoprene and other emitted BVOCs a basal emission rate of isoprene of $7.8 \mathrm{mg} \mathrm{m}^{-2} \mathrm{~h}^{-1}$ was derived. We parameterise fluxes of depositing compounds using a resistance approach using direct canopy measurements of deposition. Consistent with Karl et al. (2010), we also propose that it is important to include deposition in flux models, especially for secondary oxidation products, in order to improve flux predictions.
\end{abstract}

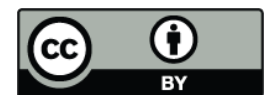

Correspondence to: P. K. Misztal (pkm@berkeley.edu)

\section{Introduction}

Emissions of biogenic volatile organic compounds (BVOCs) constitute approximately $90 \%$ of all atmospheric volatile organic compounds (VOCs), half of which are contributed by one compound - isoprene, which has an estimated global annual emission from vegetation of $\sim 600 \mathrm{Tg}$ (Guenther et al., 2006). VOCs play many important roles in atmospheric chemistry, for example serving as sinks for $\mathrm{OH}$ radicals, and thus indirectly prolonging the lifetime of pollutants and greenhouse gases in the troposphere. They also contribute to the formation of tropospheric ozone and secondary organic aerosol, and thus indirectly affect regional and global climate. Examples of important biological functions identified for VOCs include plant protection against mechanical and anoxic stress (Jardine et al., 2009), oxidative stress (Loreto and Schnitzler, 2010), thermal stress (Behnke et al., 2010), herbivore stress (Laothawornkitkul et al., 2008), attraction of pollinators (Misztal et al., 2010) and mediation in metabolic processes (e.g. Peñuelas and Staudt, 2010).

Representation of VOCs in current models has high uncertainties because of the limited number of measurements, particularly in the tropical regions which are thought to contribute half of the global VOC emissions (Karl et al., 2004). In particular, there are practically no VOC emission data for South East Asia, an area currently undergoing widespread and rapid land-use change where land that was once rainforest is now occupied by oil palm plantations (Elaeis guineensis). It has only recently been found that oil palms are very high isoprene emitters (Wilkinson et al., 2006; Owen and Penuelas, 2005; Geron et al., 2006).

Here we report the first above-canopy eddy-covariance measurements of BVOC fluxes from oil palms, by proton-

Published by Copernicus Publications on behalf of the European Geosciences Union. 
transfer-reaction mass spectrometry (PTR-MS), which were made as part of two overlapping projects: Oxidant and Particle Photochemical Processes (OP3) and Aerosol Coupling in the Earth System (ACES). These projects featured VOC flux and other atmospheric measurements at two contrasting sites: a secondary rainforest, and an oil palm plantation, about $80 \mathrm{~km}$ apart. The detailed list of measurements can be found in the introductory overview paper for these field campaigns (Hewitt et al., 2010). An overview of the flux measurements is given in Fowler et al. (2011); an overview of atmospheric composition measurements is given in MacKenzie et al. (2011); and an overview of regional and global aspects of the projects is given in Pyle et al. (2011). The present paper gives a much more detailed account of the BVOC fluxes over the oil palm plantation than has been provided to date.

There are currently 14 million ha of oil palm plantations worldwide (FAOSTAT, 2009), nearly 9 million ha of which are located in South East Asia. It is consequently important to understand the atmospheric chemistry occurring in this ecosystem, and the potential impacts on climate, following the change in land-use from rainforest and to a lesser degree from other habitats. The present paper focuses on oil palm; VOC fluxes from the rainforest have been reported by Langford et al. (2010). The lack of measured emission rates of BVOCs, especially from tropical regions, leads to significant uncertainties in modelling future regional (e.g. Sentian et al., 2010) and global atmospheric composition (Pyle et al., 2011).

Global modelling often has to rely on up-scaling from leaflevel emissions without the constraints imposed by the corresponding ecosystem-scale measurements. Uncertainties arise not simply because of a lack of knowledge of leaf-level emissions, but also of the model description of canopy architecture and light interception, the processes by which BVOCs are transported within and from the forest canopy, the possibility of deposition, and of chemical reactions within the canopy. Oil palms form a monoculture, which is ideal for constraining the scale-up of a frond-level measurement with above-canopy eddy covariance data. This comparison is more difficult for the rainforest, where there is great diversity of vegetation types, and where integrating ecosystem-scale measurements are particularly important.

Emission algorithms have not yet been validated for the SE Asian tropics and therefore may need adjustment by parameterisation based on the above-canopy data (see Hewitt et al., 2010 for a discussion of the impact of OP3 rainforest data on the MEGAN emissions inventory). Below are presented parameterisations for BVOC emissions from oil palms. Wilkinson et al. (2006) reported from laboratory measurements that the circadian rhythm in oil palms is particularly strong. It is likely, therefore, that use of a constant basal emission rate (BER) might lead to either overestimation or underestimation of emission rates depending on the time that a leaf-level BER is taken. Evidence of circadian control at the canopy scale will be investigated in a separate manuscript. As an initial approach, the parameterisation of the G06 algorithm (Guenther et al., 2006) uses a constant BER. However, general variability in the BER is known (Niinemets et al., 2010a, b) and the current definition regards the BER as an average of a range of representative values.

\section{Methodology}

\subsection{Site and sampling system}

The experiment was conducted in the NE part of Borneo, in the Sabah province of Malaysia, in May-June 2008. The experimental site $\left(5^{\circ} 14^{\prime} 52.67^{\prime \prime} \mathrm{N}\right.$ latitude, $118^{\circ} 27^{\prime} 14.96^{\prime \prime} \mathrm{E}$ longitude) was located within a flat 33 ha zone of commercial oil palm plantation surrounded by a much larger oil palm area belonging to the Sabahmas Oil Palm Plantation and owned by Wilmar International Ltd. The nearest town is Lahad Datu (156000 inhabitants) at a distance of $28 \mathrm{~km} \mathrm{NE}$. The palms were 12 year old $E$. guineensis $\times$ E. oleifera hybrids of the progeny "Gutherie", with an average height of $12 \mathrm{~m}$, a single-sided leaf area index (LAI) of about 6 , and a commercial planting density of 124 trees ha ${ }^{-1}$. A summary of atmospheric measurements as part of the OP3 and ACES projects at this site has been presented elsewhere (Hewitt et al., 2010; MacKenzie et al., 2011). The instrumentation for the BVOC flux measurements was as described by Misztal et al. (2010). The sampling inlet of a $20 \mathrm{~m}$ PTFE tube (1/4" OD) was attached at a height of $15 \mathrm{~m}$ above ground, close to a sonic anemometer (Gill Solent R3 operated at $20 \mathrm{~Hz}$ ), on a pumpup mast. The other end was connected to a $351 \mathrm{~min}^{-1}$ pump and the PTR-MS, housed in an air conditioned shed erected below the canopy, sub-sampled continuously at a flow rate of $0.41 \mathrm{~min}^{-1}$. The ground-level section of the tubing, including the solenoid valves, was heated by a resistance heating tape (Omega, UK type SRF3-2C self-regulating heat cable) to $40^{\circ} \mathrm{C}$ and insulated by a polymer foam sleeve in order to prevent water condensation. The high flow rate in the main line had two purposes: (1) to maintain a high Reynolds number $(R e>6000)$ in the tubing, as required for measuring the turbulent eddy covariance flux, and (2) to ensure reduced line pressure, thereby protecting against condensation.

\subsection{Proton transfer reaction mass spectrometry (PTR-MS)}

The volume mixing ratios and eddy fluxes of biogenic volatile organic compounds (BVOCs) were measured by a Proton-Transfer-Reaction Mass Spectrometer (PTR-MS) operated in continuous flow disjunct eddy covariance (cfDEC) mode, also referred to as virtual disjunct eddy covariance (vDEC). The PTR-MS entered flux mode for $25 \mathrm{~min}$ of each half an hour period, during which selected target $\mathrm{m} / \mathrm{z}$ (see Table 1) were measured at high frequency, with dwell times of $500 \mathrm{~ms}$. The remaining $5 \mathrm{~min}$ were alternately spent on sampling zero air and on scanning the entire $\mathrm{m} / \mathrm{z}$ range from 
Table 1. Statistical summary (11 days) of volume mixing ratios (ppbv) of 11 targeted VOCs.

\begin{tabular}{|c|c|c|c|c|c|c|c|c|c|c|c|c|}
\hline $\mathrm{m} / \mathrm{z}$ & 33 & 45 & 59 & 69 & 71 & $75^{\mathrm{a}}$ & $81^{\mathrm{b}}$ & 83 & 93 & $137^{\mathrm{b}}$ & 149 & 205 \\
\hline Compound & Methanol & Acetaldehyde & Acetone & Isoprene & MVK MACR & HA & MT & Hexanals & Toluene & MT & Estragole & SQT \\
\hline \multicolumn{13}{|l|}{ 24-h statistics } \\
\hline Arithmetic mean & 0.75 & 0.54 & 0.67 & 4.28 & 0.86 & 2.24 & 0.33 & 0.49 & 1.62 & 0.33 & 2.98 & 0.17 \\
\hline Arithmetic mean [graphical] & 0.79 & 0.48 & 0.63 & $\mathrm{n} / \mathrm{a}$ & $\mathrm{n} / \mathrm{a}$ & $\mathrm{n} / \mathrm{a}$ & 0.31 & 0.40 & 1.50 & 0.36 & 2.84 & 0.13 \\
\hline Geometric mean & 0.59 & 0.42 & 0.61 & 1.29 & 0.22 & 1.99 & 0.28 & 0.34 & 1.22 & 0.30 & 2.70 & 0.14 \\
\hline Geometric mean [graphical] & 0.55 & 0.48 & 0.61 & $\mathrm{n} / \mathrm{a}$ & $\mathrm{n} / \mathrm{a}$ & $\mathrm{n} / \mathrm{a}$ & 0.30 & 0.38 & 1.73 & 0.36 & 2.83 & 0.18 \\
\hline$\sigma$ & 0.63 & 0.40 & 0.28 & 6.15 & 1.30 & 0.98 & 0.19 & 0.40 & 1.08 & 0.19 & 1.31 & 0.12 \\
\hline$\sigma$ [graphical] & 0.26 & 0.40 & 0.28 & $\mathrm{n} / \mathrm{a}$ & $\mathrm{n} / \mathrm{a}$ & $\mathrm{n} / \mathrm{a}$ & 0.16 & 0.40 & 1.14 & 0.24 & 1.42 & 0.15 \\
\hline$\sigma_{\mathrm{geo}}$ & 1.88 & 2.02 & 1.49 & 5.10 & 6.31 & 1.69 & 1.73 & 2.47 & 2.33 & 1.50 & 1.59 & 1.75 \\
\hline$\sigma_{\text {geo }}$ [graphical] & 2.14 & 1.97 & 1.52 & $\mathrm{n} / \mathrm{a}$ & $\mathrm{n} / \mathrm{a}$ & $\mathrm{n} / \mathrm{a}$ & 1.64 & 2.56 & 3.39 & 1.64 & 1.72 & 1.65 \\
\hline Median & 0.39 & 0.48 & 0.61 & 0.86 & 0.22 & 2.18 & 0.18 & 0.40 & 1.51 & 0.25 & 2.81 & 0.10 \\
\hline Max & 4.40 & 2.50 & 1.90 & 26.0 & 6.06 & 4.7 & 1.00 & 2.42 & 5.5 & 1.08 & 8.10 & 0.90 \\
\hline Min & $<0.39$ & $<0.20$ & 0.26 & 0.00 & 0.00 & 0.24 & $<0.18$ & $<0.10$ & $<0.20$ & $<0.25$ & 0.51 & $<0.10$ \\
\hline 5th percentile & 0.39 & 0.20 & 0.33 & 0.17 & 0.02 & 0.72 & 0.18 & 0.10 & 0.20 & 0.25 & 1.23 & 0.10 \\
\hline 95th percentile & 2.04 & 1.28 & 1.14 & 18.5 & 3.73 & 3.97 & 0.71 & 1.25 & 3.47 & 0.83 & 5.28 & 0.42 \\
\hline$N$ & 511 & 511 & 511 & 511 & 511 & 237 & 511 & 511 & 511 & 511 & 511 & 511 \\
\hline$\%$ filled with $0.5 \mathrm{LOD}$ & 66.5 & 43.1 & 0.00 & 0.0 & 0.0 & 0.0 & 55.2 & 29.4 & 8.0 & 84.9 & 0.00 & 67.3 \\
\hline $\operatorname{LOD}\left[2 \sigma_{\mathrm{ZA}} / S_{\mathrm{norm}}\right]$ & 1.5 & 0.50 & 0.02 & 0.05 & 0.04 & 0.10 & 0.35 & 0.42 & 0.43 & 0.62 & 0.5 & 0.28 \\
\hline LOD [graphical] & 0.78 & 0.40 & $\mathrm{n} / \mathrm{a}$ & $\mathrm{n} / \mathrm{a}$ & $\mathrm{n} / \mathrm{a}$ & $\mathrm{n} / \mathrm{a}$ & 0.32 & 0.20 & 0.41 & 0.46 & $\mathrm{n} / \mathrm{a}$ & 0.20 \\
\hline$\%$ total VOC & 5 & 4 & 4 & 29 & 6 & 15 & 2 & 3 & 11 & $\mathrm{~b}$ & 20 & 1 \\
\hline \multicolumn{13}{|c|}{ Statistics for midday only (10:00-14:00 LT) } \\
\hline Arithmetic mean & 0.92 & 0.61 & 0.93 & 13.1 & 2.56 & 2.35 & 0.42 & 0.94 & 1.81 & 0.34 & 3.16 & 0.13 \\
\hline Geometric mean & 0.72 & 0.48 & 0.91 & 11.7 & 2.06 & 2.22 & 0.37 & 0.88 & 1.66 & 0.30 & 2.91 & 0.12 \\
\hline$\sigma$ & 0.68 & 0.41 & 0.20 & 5.35 & 1.45 & 0.81 & 0.21 & 0.33 & 0.67 & 0.19 & 1.00 & 0.06 \\
\hline Median & 0.39 & 0.57 & 0.88 & 13.8 & 2.52 & 2.18 & 0.43 & 0.95 & 1.73 & 0.25 & 2.96 & 0.10 \\
\hline$\sigma_{\text {geo }}$ & 1.99 & 2.10 & 1.21 & 1.70 & 2.11 & 1.41 & 1.74 & 1.48 & 1.62 & 1.51 & 1.49 & 1.43 \\
\hline 5th percentile & 0.39 & 0.20 & 0.71 & 4.16 & 0.41 & 1.43 & 0.18 & 0.49 & 0.79 & 0.25 & 1.78 & 0.10 \\
\hline 95th percentile & 2.19 & 1.29 & 1.39 & 21.4 & 5.20 & 3.92 & 0.86 & 1.47 & 2.84 & 0.79 & 5.01 & 0.26 \\
\hline$N(N<\mathrm{LOD})$ & $88(45)$ & $88(34)$ & $88(0)$ & $88(0)$ & $88(0)$ & $40(0)$ & $88(28)$ & $88(0)$ & $88(2)$ & $88(73)$ & $88(0)$ & $88(74)$ \\
\hline$\%$ total VOC & 6 & 2 & 3 & 49 & 8 & 8 & 2 & 4 & 6 & $\mathrm{~b}$ & 12 & $<1$ \\
\hline
\end{tabular}

a Derived from 5-min hourly mass scans; upper limit due to interferences with possible propionates at $m / z 75$.

b Monoterpenes (MT) were calibrated to yield absolute concentrations independently at $\mathrm{m} / \mathrm{z} 81$ and $\mathrm{m} / \mathrm{z} 137$. The more sensitive signal at $m / z$, was used instead of their average.

21 to $206 \mathrm{amu}$, to record the average composition of the air. The methodology for derivation of volume mixing ratios and fluxes is presented in the Supplement to this article.

\subsection{Parameterisation of flux algorithms for oil palms}

\subsubsection{Isoprene emission}

The isoprene flux measured by the disjunct eddy covariance technique provides a useful validation and constraint tool for emission models for this vegetation type. The G06 algorithm (Guenther et al., 2006) is an emissions model driven by two environmental variables: temperature and photosynthetic active radiation (PAR) and is an improvement on the former G95 model (Guenther et al., 1995) by including data on the history of those variables. Past conditions contribute to isoprene emission control through their effect on enzyme (isoprene synthase) kinetics (Fall and Wildermuth, 1998) and substrate (dimethylallyl pyrophosphate (DMAPP)) availability, and allow for a better reproduction of short- and longterm variability.

Normally these algorithms are parameterised with leaflevel data using the temperature of the leaf surface in the cuvette. However, measurements by eddy covariance above canopy normally use the ambient temperature from a sensor close to the sampling inlet. Average canopy temperature $\left(T_{\mathrm{c}}\right)$ as estimated from the "big-leaf" resistance analogy (e.g. Nemitz et al., 2009c; Singles et al., 1998) was found to be on average $2-3{ }^{\circ} \mathrm{C}$ higher than the ambient air temperature $\left(T_{\mathrm{a}}\left(z_{\mathrm{m}}\right)\right)$ during daytime (refer to Supplement SI-1). Thus, $T_{\mathrm{c}}$ should be used in parameterisations of emission and deposition for consistency with the leaf level approach. The PAR may have different effects on the temperature of the sun-lit and sun-shaded leaves, so the actual temperature of individual leaves can significantly deviate from $T_{\mathrm{c}}$.

One version of the G06 algorithm includes a canopy environment model (CEM) to scale up the leaf level parameterisation to simulate directly the canopy flux $\left(\mathrm{mg} \mathrm{m}^{-2} \mathrm{~h}^{-1}\right)$. This makes it convenient for comparison with canopy flux measured data, such as from eddy covariance, to be used for model testing, constraint and parameterisation, but one should bear in mind that the comparison may differ if the G06 leaf-level algorithm is scaled up using a different CEM. Ten parameters have been chosen and labelled analogously to those in equations presented for estragole emission parameterisation by Misztal et al. (2010). Details are given in the Supplement (SI-8). Parameterised flux calculations are used to fill data gaps in the data time series (see Sect. 3.2, below). 
These parameterisations are only representative for the particular canopy structure of oil palm but may differ in other regions. The parameterised canopy environmental emission activity (PCEEA) did not improve the fit at the rainforest (Langford et al., 2010) so it was not tested with these data. Since the average canopy temperature was used, the parameterised algorithm represents the "big-leaf" emission response and the optimised parameters should be treated with caution in referring to different oil palm environments; their biological interpretation needs to be explored at leaf level scale.

\subsubsection{Methyl vinyl ketone (MVK) and methacrolein (MACR) deposition}

Proton transfer reaction causes both MVK and MACR to fragment to the same ion $(\mathrm{m} / \mathrm{z}, 71)$ and thus only the sum of the two compounds can be quantified by standard PTR-MS. Fluxes of MVK + MACR were derived with the same technique as isoprene fluxes, and were shown to be downwards, i.e. deposition to the canopy. The measured fluxes presented in Sect. 3.3.2 have been used to derive MVK + MACR deposition velocity $\left(V_{\mathrm{d}}\right)$ using the relationship:

$V_{\mathrm{d}}\left(z_{\mathrm{m}}\right)=-F \cdot \chi\left(z_{\mathrm{m}}\right)^{-1}$.

where $F$ is the measured flux of MVK and MACR, and $\chi\left(z_{\mathrm{m}}\right)$ is the measured volume mixing ratio of MVK and MACR at the measurement height $\left(z_{\mathrm{m}}=15 \mathrm{~m}\right)$.

The deposition velocity can also be represented using the resistance approach (Nemitz et al., 2009c; Singles et al., 1998; Sutton et al., 1995) as:

$V_{d}(z)=\frac{1}{R_{\mathrm{a}}(z-d)+R_{\mathrm{b}}+R_{\mathrm{c}}}$

where $R_{\mathrm{a}}$ is the aerodynamic resistance, $R_{\mathrm{b}}$ is the laminar boundary layer resistance close to the surface of the leaves, $R_{\mathrm{c}}$ is the canopy resistance, and $d$ is the zero-plane displacement height. $R_{\mathrm{a}}$ and $R_{\mathrm{b}}$ were obtained from measured micrometeorological parameters as described by Nemitz et al. (2009b). The molecular diffusivity in air $D_{\mathrm{a}}$ for MVK $\left(1.00 \times 10^{-6} \mathrm{~m}^{2} \mathrm{~s}^{-1}\right)$, required in the Schmidt number which is part of the Stanton number which in turn is part of the $R_{\mathrm{b}}$ equation, was obtained from the molecular structure online calculator (EPA, 2007) as the average value of the Wilke and Lee (WL), the Fuller, Schettler and Giddings (FSG) and the FSG with LaBas molar volume (FSG/LaBas) estimation methods of diffusion coefficients in air. For modelling the MVK+MACR flux time series the canopy resistance $\left(R_{\mathrm{c}}\right)$ is required, which was obtained by substituting $V_{\mathrm{d}}(z)$ in Eq. (2) and rearranging the equation to yield $R_{\mathrm{c}}$.

Deposition to a vegetation canopy is constrained by the maximum deposition velocity $\left(V_{\max }\right)$ that would be obtained if deposition were only constrained by turbulence and diffusion (i.e. $R_{\mathrm{c}}=0$ ):

$V_{\mathrm{d} \max }=\left(R_{\mathrm{a}}(z-d)+R_{\mathrm{b}}\right)^{-1}$.
The deposition fluxes were parameterised similarly to $\mathrm{Ne}-$ mitz et al. (2009a) (N09) except that instead of taking the average value of $V_{\mathrm{d}}$, the fitting of a diurnal function to the available time series of $R_{\mathrm{c}}$ was made, with which the flux time series was inferred from the available measured mixing ratio data $\left(\chi\left(z_{\mathrm{m}}\right)\right)$ and $V_{\mathrm{d}}$ as:

$F_{\mathrm{MVK}+\mathrm{MACR}}=-\frac{\chi\left(z_{m}\right)}{R_{\mathrm{a}}(z-d)+R_{\mathrm{b}}+R_{\mathrm{c}}}$

The fluxes modelled in this way were used for gap-filling as shown in Fig. 4 below.

\subsection{Levels of uncertainty}

Although much effort was expended to maximise the quality and precision of the measurements, uncertainties still remain. The main sources of uncertainty are likely to result from the relatively short measurement period of 12 days. As was shown using the temperature and PAR values recorded prior to the PTR-MS measurements, the isoprene emissions would have been almost a factor of two higher during the preceding period. Using the combination of measurement and optimised modelling approaches the data for the 3 weeks could be reconstructed, which should form a representative picture of the fluxes during the May/June period. The variations in temperature in different months should be considered, although the climate in Sabah has only weak seasonality compared, for example, with the Amazon, which is also reflected in the absence of a large seasonality in the VOC flux above the forest (Langford et al., 2010). The absolute humidity in Sabah was very high. This could have an effect on somewhat elevated LODs for compounds such as methanol or acetaldehyde, although both the sensitivity and the LOD were in the typical range for isoprene.

The calibration standard was not only used to calibrate a range of compounds directly, but also to investigate the uncertainty for deriving mixing ratios with the relative transmission approach. These uncertainties were found to be higher for large $m / z$ (SI-3). The errors deriving from disjunct sampling and the number of masses in a cycle and dwell time used were typical for other vDEC setups. Flux errors and their quality control are discussed in SI-5. The modelling approaches and parameterisations are performed with the main aim of using the optimised model for gap-filling.

\section{Results and discussion}

\subsection{Volume mixing ratios (VMRs) of dominant VOCs}

The diverse VOC mix of compounds recorded by PTR-MS can be seen on an averaged mass scan for the entire measurement period (Fig. 1a). In addition, summary statistics for the 11 dominant compounds selected for the flux mode are presented in Table 1, separately for the total period and for the 

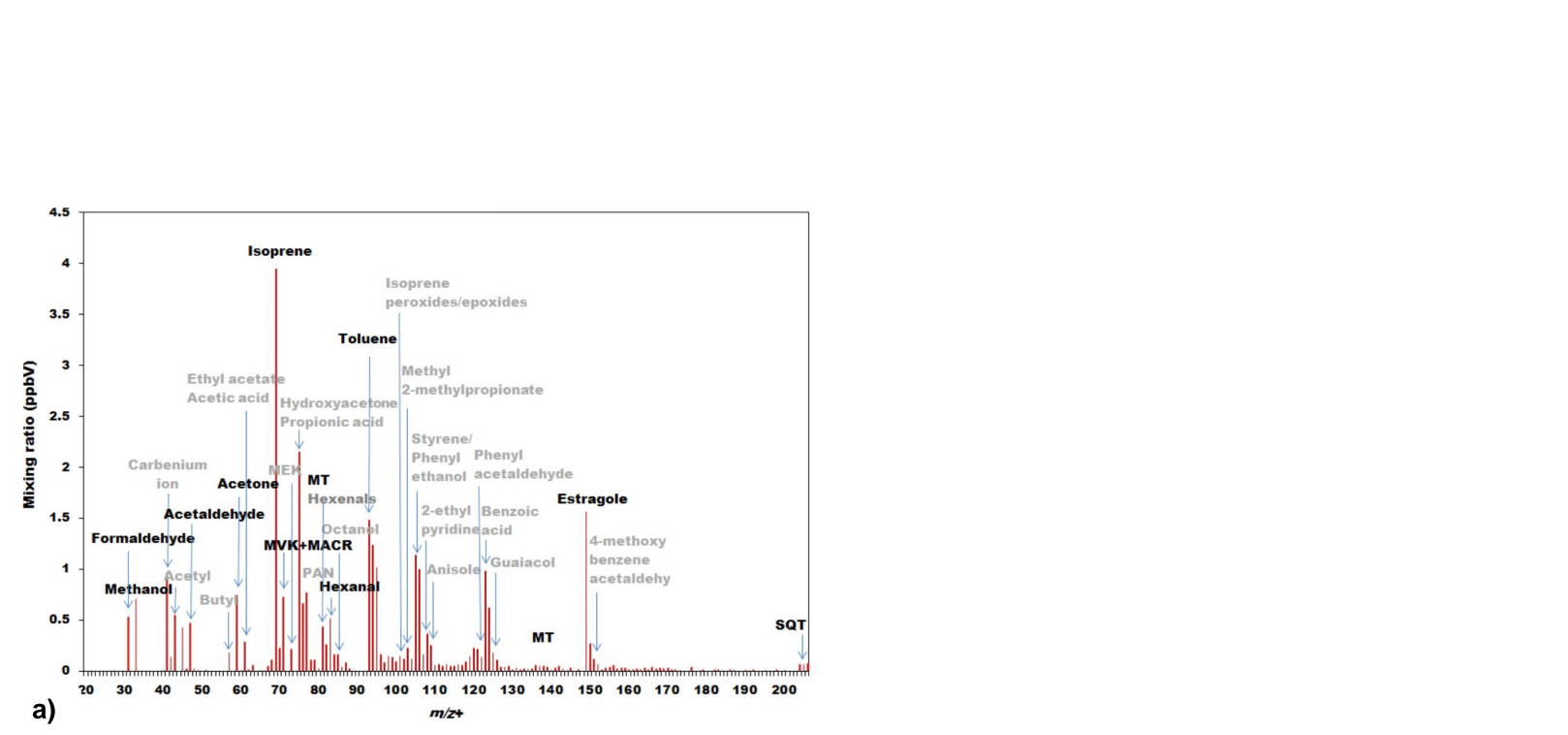

Fig. 1. (a) VOC composition at the oil palm plantation; averaged data of the campaign. Compounds whose identification was not entirely unambiguous are presented in grey; (b) relative comparison to rainforest (see Sect. 3.6).

midday (10:00-14:00) time range. The concentration time series presented in Table 3 were derived by averaging the high frequency mixing ratios of compounds included in the flux mode, with the exception of hydroxyacetone which was retrieved from the $5 \mathrm{~min}$ scans performed every hour. The identification and attribution of the compounds was based on expected contributions to each $\mathrm{m} / \mathrm{z}$ from the literature and confirmed by a portable GC-MS at the site and numerous GC cartridge samples of frond, inflorescence enclosures and also of ambient air near the ground and on the tower. Details on GC analysis and a sample chromatogram were presented in Misztal et al. (2010). Because of GC and GC-cartridge limitations, certain compounds (e.g. oxygenated, short lived) or all the contributions might not be unambiguously identified, and therefore less certain compound attributions are presented as grey in Fig. 1a.

Reliable estimates of volume mixing ratios are only possible when a statistically sufficient sample of a population can be measured. The PTR-MS collects thousands of samples in $30 \mathrm{~min}$, so a $30 \mathrm{~min}$ mean can be considered statistically valid if the characteristics of the population are not changing rapidly and the measured values exceed the limit of detection (LOD). The commonly used approach for the derivation of an LOD is twice the standard deviation of the noise (as normalised counts of the representative zero air measurement) divided by the normalised sensitivity (e.g. Davison et al., 2009; Langford et al., 2009a, 2009b; Misztal et al., 2010; Rinne et al., 2007; Taipale et al., 2008).

The detection limits vary between compounds, and depend on the instrument conditions and dwell time. Typically, for small $\mathrm{m} / \mathrm{z}$ a high background is the most significant fac- tor affecting the LOD. High backgrounds for methanol and acetaldehyde are sometimes encountered (Eerdekens et al., 2009; Murphy et al., 2010) and they were also relatively high for these two compounds in Borneo both at the rainforest (Langford et al., 2010) and the plantation (this work). However, the same instrument had a very low detection limit for those compounds during the ACCENT-VOCBAS campaign in Italy (Davison et al., 2009). The cause of these differences is not entirely clear; for example $\mathrm{O}^{17} \mathrm{O}^{+}, \mathrm{O}_{2} \mathrm{H}^{+}$or $\mathrm{DNOH}^{+}$ions may be in part responsible for the interference at $m / z, 33$ (Müller et al., 2010), but the correlation of $\mathrm{m} / z 32$ with $m / z 33$ signal was low $\left(r^{2}=0.082\right)$, so the contribution from these ions must have been relatively small. Contamination of the water reservoir with methanol is one of the possibilities. The noise at $m / z 33$ might also come from methanol forming adducts with water cluster at high humidity, but this was not observed in a correlation of $\mathrm{m} / \mathrm{z} 33$ with $\mathrm{m} / \mathrm{z}, 37$ which was absent $\left(r^{2}<0.01\right)$. For the higher molecular $m / z$ channels (e.g. 137, 149, 205) the background noise variations are not as significant as the reduction in sensitivities caused by the fringing effect of the quadrupole (Kim et al., 2009) related to decreases in transmission efficiency. Nevertheless, the LODs for isoprene, MVK and acetone were very low even despite the relatively high $E / N$ ratio used as a compensating measure for high humidity. The optimal situation is when all data points for a compound exceed the detection limit, but it is quite common for environmental data sets to contain mixing ratios close to zero, for example at night. For compounds which have a proportion of their concentration data below the LOD, but whose concentration distributions follow normal or lognormal distributions, the data below the 
LOD can be replaced by half the LOD value to produce a reliable average (Caudill et al., 2007; Clarke, 1998; Porter et al., 1988). This approach usually works better than the regression methods to back-estimate the data below LOD from probability plots (e.g. Helsel, 1990), mainly because of the uncertainties of the predictions of the missing distribution. The distributions of mixing ratios of the targeted compounds (i.e., those included in the flux mode) and their detection limits are shown in the Supplement (Fig. S4). Based on these, the compounds selected to undergo a statistical treatment of the data below detection limit were methanol, monoterpenes (MT), sesquiterpenes (SQT), acetaldehyde, hexanals, and toluene, whereas acetone, estragole, isoprene and MVK + MACR were considered representative in their full dataset. In the summary statistics for the whole measurement period (day and night data) (Table 1) the LODs, means and standard deviations are compared with those derived from the relationship of the ranked data with standard normal cumulative distributions. Details of the graphical procedure used are given in the Supplement (Fig. S2).

The summary statistics for the volume mixing ratio data during the mid-day period (10:00-14:00 LT) presented in Table 1 show that most compounds had much higher mixing ratios during the day; the relative percentage contributions of each compound to the total VOC mix also varied diurnally.

Campaign-averaged diurnal variations in the volume mixing ratios of the dominant VOCs are presented in Fig. 3ak. A clear diurnal pattern in mixing ratios was present for isoprene, MVK+MACR, estragole, hydroxyacetone, toluene, acetone and hexanals. In contrast, methanol, acetaldehyde, total monoterpenes (MT) and total sesquiterpenes (SQT) did not follow a clear diurnal course.

\subsection{Fluxes of dominant VOCs}

Not all the compounds which were abundant in terms of mixing ratios had large measured fluxes (Fig. 4). The summary statistics for compounds monitored in the flux mode are presented in Table 2 for the entire period (12 days) and for the midday range (10:00-14:00 LT). In addition, values are given in parenthesis for the gap-filled data with the G06 algorithm optimised specifically for isoprene, estragole and toluene (see Sect. 3.5.2 below), and with the Nemitz et al. (2009c) resistance approach adapted for MVK + MACR. The results of the parameterisations are given later in Sect. 3.5. In some cases gap-filling can change the averaged values quite substantially, since all the near-zero values are used in the computation. Without the gap-filling only the available data would be averaged which would be skewed towards larger values such as encountered during the day time, when there is a higher likelihood of fulfilling the flux quality criteria. Thus the gap-filling approach leads to a more representative dataset, which is substantiated by the good agreement between the measurement and optimised models even for floral species such as estragole and possibly floral toluene. On the other hand, gap-filling with an emission-only model does not reflect deposition, which is probably a minor component and could be accounted for as a loss in emission.

The relative percentages of VOC fluxes for the different compounds in relation to the absolute fluxes, emission only or for gap-filled data for the entire period are also showed in Table 2.

Fluxes of the most abundant compounds are presented as diurnal time series in Fig. 5. Isoprene fluxes peaked at around 11:00 LT. It was typical for a heavy rain episode to occur at around 12:00 LT causing a dip in PAR, which also can be seen in the pattern for the isoprene flux. This differed from the rainforest where rain typically occurred in the afternoon (Langford et al., 2010), but note that the two measurement campaigns were not simultaneous (see Fowler et al., 2011, for further discussion of the impact of land-use change on trace gas and heat and momentum fluxes in general).

\subsection{Characterisation of abundant VOCs}

\subsubsection{Isoprene $\left(m / z^{+} 69\right)$}

The most abundant compound at the plantation was isoprene, which reached mid-day averages of around $13 \mathrm{ppbv}$ (maximal values of $26 \mathrm{ppbv}$ ), which constituted nearly half of the total VOC mixing ratios, measured in the MID mode plus hydroxyacetone from scans, during the daytime and one third over the entire period. Because isoprene was not emitted in the dark and has a short atmospheric lifetime, its mixing ratio was close to zero at night.

Isoprene also dominated a different VOC mix at the rainforest, although its absolute values were several times lower than those presented here (Langford et al., 2010). It has been known that oil palm is a very high isoprene emitter (Wilkinson et al., 2006) in the laboratory, and our measurements confirm this high emission at the canopy scale in the field. Other differences in atmospheric composition between oil palm and rainforest are due to the agro-industrial nature of oil palm plantations, as discussed in MacKenzie et al. (2011). The measurements of large emissions are consistent with the identification of a significant contribution of isoprene oxidation products to the organic aerosol loading above both oil palm and forest by Robinson et al. (2011).

In general, isoprene detection by PTR-MS at $\mathrm{m} / z 69$ shows good agreement with GC-MS detection of isoprene reported in various studies (de Gouw and Warneke, 2007; Kuster et al., 2004), despite a notable interference at $m / z 69$ potentially deriving from a fragment of prenol (2-methyl-3-buten-2-ol) (Holzinger et al., 2005), and/or 1-penten-3-ol (Karl et al., 2001 ), both of which can also be detected at $m / z$ 87. However, no elevated signal at $\mathrm{m} / \mathrm{z} 87$ was observed and neither of these compounds were detected in leaf cuvette air by GCMS (Owen et al., 2011). Another potential interference could be from furan, a tracer of biomass burning (Christian et al., 2004) and a few anthropogenic compounds (de Gouw 
Table 2. Summary statistics for eddy covariance BVOC fluxes above the oil palm plantation (total measurement period and midday). In parentheses are given statistics values for fluxes gap-filled using approaches discussed in Sect. 3.5; E - emission, D - deposition, GF gap-filled (note only Isoprene, Estragole, Toluene, and MVK + MACR were gap-filled).

\begin{tabular}{|c|c|c|c|c|c|c|c|c|c|}
\hline$m / z$ & 33 & 45 & 59 & 69 & 71 & 81 & 83 & 93 & 149 \\
\hline & Methanol & Acetal-dehyde & Acetone & Isoprene & MVK + MACR & MT & Hexanals & Toluene & Estragole \\
\hline \multicolumn{10}{|l|}{ 24-h statistics } \\
\hline Max & 0.345 & 0.473 & 0.270 & $28.9(28.9)$ & $0.398(0.398)$ & 0.378 & 0.813 & $3.39(3.39)$ & $2.07(2.12)$ \\
\hline Min & -0.360 & -0.183 & -0.092 & $-2.39(-2.39)$ & $-1.42(-1.42)$ & -0.966 & -0.436 & $-0.367(-0.367)$ & $-0.774(-0.774)$ \\
\hline Mean & -0.044 & 0.010 & 0.012 & $4.39(2.12)$ & $-0.119(-0.053)$ & -0.026 & 0.012 & $0.353(0.186)$ & $0.440(0.398)$ \\
\hline Median & -0.024 & 0.004 & 0.002 & $1.10(0.027)$ & $-0.064(-0.003)$ & -0.023 & 0.014 & $0.152(0.009)$ & $0.249(0.165)$ \\
\hline$\sigma$ & 0.107 & 0.074 & 0.050 & $6.37(4.70)$ & $0.212(0.144)$ & 0.227 & 0.180 & $0.513(0.382)$ & $0.629(0.497)$ \\
\hline 5 th percentile & -0.223 & -0.102 & -0.041 & $-0.063(-0.018)$ & $-0.512(-0.247)$ & -0.450 & -0.264 & $-0.103(-0.005)$ & $-0.341(0.000)$ \\
\hline 95 th percentile & 0.100 & 0.137 & 0.096 & $19.2(12.8)$ & $0.054(0.008)$ & 0.328 & 0.255 & $1.18(0.990)$ & $1.61(1.44)$ \\
\hline$N$ & 163 & 173 & 167 & $213(633)$ & $205(529)$ & 81 & 77 & $153(633)$ & $109(633)$ \\
\hline$\%$ total VOC $(\mathrm{E}+\mathrm{D})$ & -1 & 0.2 & 0.2 & 82 & -2 & -0.3 & 0.2 & 7 & 8 \\
\hline$\%$ total VOC (only E) & - & 0.2 & 0.2 & 84 & - & - & 0.2 & 7 & 9 \\
\hline$\%$ total VOC $(\mathrm{E}+\mathrm{D}) \mathrm{GF}$ & -2 & 0.4 & 0.4 & 74 & -2 & -0.9 & 0.3 & 7 & 14 \\
\hline \multicolumn{10}{|c|}{ Statistics for midday only (10:00-14:00 LT) } \\
\hline Max & 0.226 & 0.473 & 0.194 & $28.94(28.94)$ & $0.398(0.398)$ & 0.373 & 0.483 & $3.390(3.390)$ & $1.635(1.821)$ \\
\hline Min & -0.342 & -0.154 & -0.076 & $-2.392(-2.392)$ & $-0.973(-0.973)$ & -0.502 & -0.382 & $0.102(0.020)$ & $-0.088(-0.088)$ \\
\hline Mean & -0.098 & 0.041 & 0.030 & $9.707(8.370)$ & $-0.220(-0.173)$ & -0.042 & 0.029 & $0.763(0.684)$ & $0.807(0.920)$ \\
\hline Median & -0.098 & 0.033 & 0.026 & $8.446(7.025)$ & $-0.154(-0.123)$ & -0.057 & 0.043 & $0.605(0.560)$ & $0.718(0.866)$ \\
\hline$\sigma$ & 0.120 & 0.094 & 0.054 & $7.185(6.957)$ & $0.237(0.210)$ & 0.237 & 0.234 & $0.582(0.551)$ & $0.542(0.405)$ \\
\hline 5th percentile & -0.278 & -0.052 & -0.037 & $0.862(0.477)$ & $-0.617(-0.529)$ & -0.477 & -0.334 & $0.144(0.061)$ & $0.003(0.315)$ \\
\hline 95 th percentile & 0.066 & 0.177 & 0.120 & $20.62(20.03)$ & $0.013(0.003)$ & 0.351 & 0.417 & $1.751(1.776)$ & $1.601(1.636)$ \\
\hline$N$ & 44 & 52 & 53 & $64(100)$ & $60(88)$ & 18 & 20 & $45(100)$ & $26(100)$ \\
\hline$\%$ total VOC $(\mathrm{E}+\mathrm{D})$ & -1 & 0.3 & 0.3 & 83 & -2 & -0.4 & 0.2 & 7 & 7 \\
\hline$\%$ total VOC (only E) & - & 0.4 & 0.3 & 85 & - & - & 0.3 & 7 & 7 \\
\hline$\%$ total VOC $(\mathrm{E}+\mathrm{D}) \mathrm{GF}$ & -0.4 & 0.4 & 0.3 & 81 & -2 & -0.4 & 0.3 & 7 & 9 \\
\hline
\end{tabular}

et al., 2003), but the signal of acetonitrile at $\mathrm{m} / \mathrm{z}$ 42, another biomass burning compound, and of benzene at $m / z$, 79, an anthropogenic indicator, were both very low in the mass scans (see also Hewitt et al., 2009, Fig. 2 and associated discussion). Therefore considering the magnitude of isoprene emissions and its clear diurnal trends it is extremely unlikely that any interferences were significant.

Isoprene showed mainly emission, and its fluxes were well correlated with canopy temperature $\left(T_{\mathrm{c}}\right)\left(r^{2}=0.84\right.$ for the exponential fit), and PAR ( $r^{2}=0.91$ for the quadratic fit). They were also well correlated with sensible heat flux $(H)$ $\left(r^{2}=0.8\right)$, in contrast to the fluxes of the first oxidation products MVK and MACR (schematic of oxidation in Fig. 6), which exhibited mainly deposition and negative correlation with $H$ (see Sect. 3.3.2).

Figure 4 shows the flux pattern following closely the variation in PAR and temperature. An exponential relationship with temperature is observed for both mixing ratios and fluxes provided that the PAR is greater than zero (Fig. 7a and $\mathrm{b}$, respectively). The isoprene flux-temperature relationship for the rainforest (not presented here) also showed an exponential fit but was much steeper for the oil palm, indicating higher sensitivity of oil palm emissions to temperature. From these dependencies it is clear that an increase in global temperatures could dramatically increase BVOC emissions from oil palm.
The steeper increase of emission with temperature may also be indicative of a stronger additional circadian rhythm in the basal emission rate which has been observed for oil palm in the laboratory (Wilkinson et al., 2006), and which is likely to be correlated with temperature. This will be explored in future analysis. The relationship between isoprene flux and PAR is shown in the Supplement (Fig. S7)

\subsubsection{MVK + MACR $\left(m / z^{+}\right.$71) deposition}

During the day, isoprene oxidation was responsible for the formation of the first-order oxidation products MVK and MACR, which followed a very similar diurnal pattern to that of isoprene with a mid-day average of $2.2 \mathrm{ppbv}$. MVK and MACR are the first-order oxidation products of isoprene and comprise over $50 \%$ of all oxidation products (Pinho et al., 2005; Taraborrelli et al., 2009). The sum of those two isomers can be detected reliably at $m / z 71$. There was a strong positive correlation between MVK+MACR and isoprene mixing ratios $\left(r^{2}=0.80\right.$, slope $\left.0.19 \pm 0.04\right)$. A similar slope of correlation was observed at the rainforest (Langford et al., 2010) despite the large difference in the measurement heights. However, the slope of this relationship was more than two times higher in measurements above the Amazon forest (Karl et al., 2009) which might indicate higher oxidative capacity in the Amazon, different chemistry caused by different recycling mechanisms or differences 


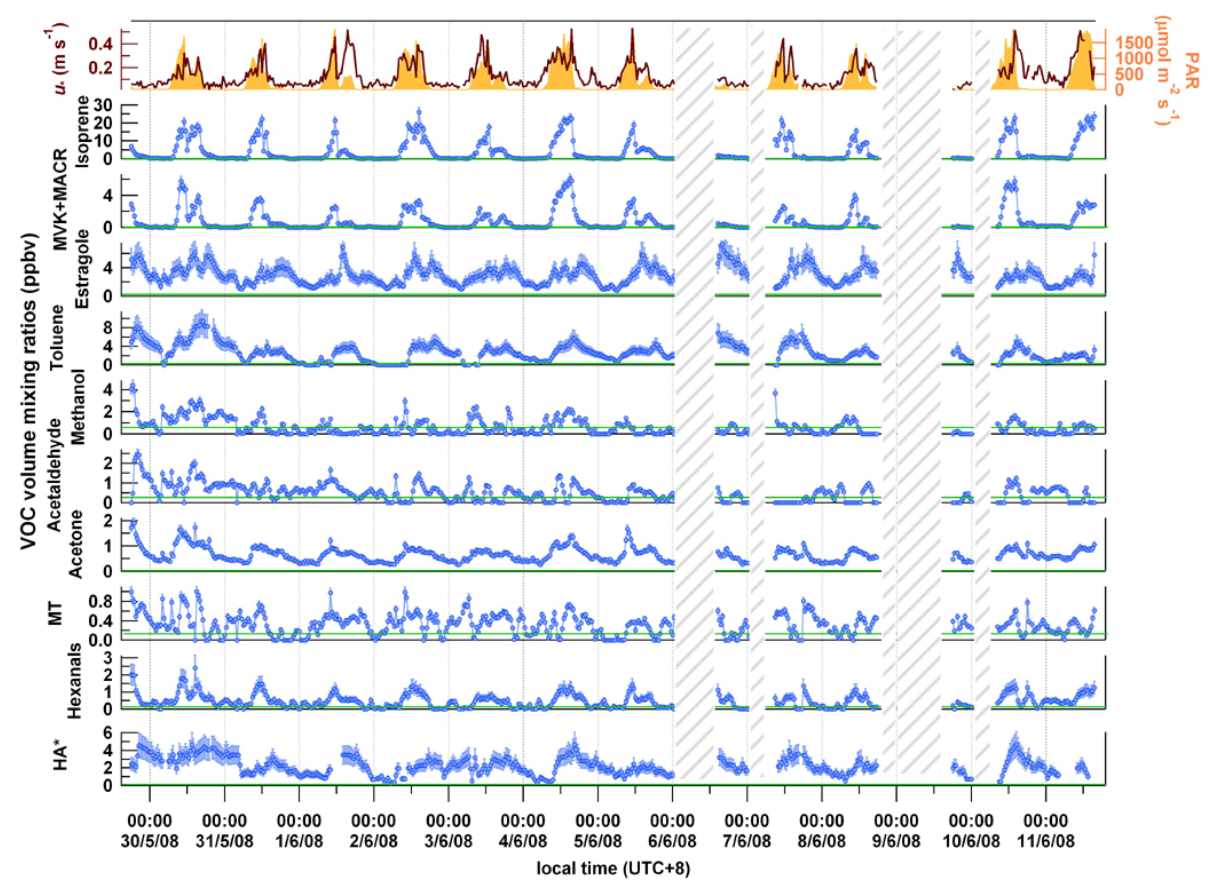

Fig. 2. Time series of volume mixing ratios of 9 compounds included in the flux mode and hydroxyacetone (* derived from the scan mode). Green lines represent LODs.

in the oxidation product losses due to wet and dry deposition. The ratio between (MVK + MACR) and isoprene was the smallest in the middle of the day (0.2), as the production rate of isoprene was exceeding the photochemical turnover, whereas ratios as high as 0.4 were observed in the morning and in the afternoon. The absolute ratio is also dependent on the source-and-sink balance of MVK + MACR which are produced with a lag time and have a longer atmospheric lifetime, relative to isoprene. Consequently, the ratio may be further affected by the dynamics in the growing boundary layer in the morning (dilution) and in the collapsing boundary layer in the evening (build-up). The correlation between isoprene flux and (MVK+MACR) flux was negative indicating that MVK and MACR were efficiently deposited (Fig. 8) at a deposition velocity $\left(V_{\mathrm{d}}\left(z_{\mathrm{m}}\right)\right)$ exceeding $1 \mathrm{~cm} \mathrm{~s}^{-1}$ during midday and at times reaching the maximum deposition velocity $\left(V_{\max }\right)$ permitted by turbulence of 1.5 to $2 \mathrm{~cm} \mathrm{~s}^{-1}$. There is mounting evidence that MVK and MACR can be taken up efficiently by plants (Karl et al., 2010). By contrast, at the Malaysian rainforest site MVK + MACR showed small net emission above the canopy (Langford et al., 2010). The local flux of a reactive compound, measured some distance above the canopy is always a combination of the surface exchange (deposition/emission) and the chemical production or destruction below the measurement height. MVK+MACR production from isoprene depends on the concentrations of $\mathrm{OH}$ and isoprene as well as the average transport time between the point of emission and the measurement height. Thus, it is unclear whether the difference between the studies reflects a difference in the efficiency of the canopies to take up these compounds, or the much larger measurement height at the forest site allowing chemical production to mask the removal at the surface. However, an in-canopy BVOC profile analysis by Ryder et al. (2011) at the forest site also indicated that MVK + MACR were emitted at the top of the canopy, suggesting that the rainforest canopy itself presented a larger source (through chemistry) than sink (due to deposition). The oil palm measurements presented here were made close to a shorter canopy, where chemical production below the measurement height makes a much smaller contribution to the measured flux.

It is likely that other oxidation products of isoprene are also effectively deposited (Karl et al., 2009, 2007; Kuhn et al., 2007). For example Karl et al. (2007) derived the highest deposition to occur at the top of the canopy and the integrated source/sink distribution over the entire canopy indicated that the primary source for these oxygenated VOCs was above the canopy. Inclusion of such high deposition velocities into models can significantly improve the agreement of model with measurements (Pugh et al., 2010). Flux measurements of deposition are therefore urgently needed to quantify deposition of various compounds to a range of plant canopies.

Through the efficient deposition of MVK and MACR the plants $R e$-captured some of the carbon lost by the primary BVOC emission, as recently pointed out by Karl et al. (2010). Some other VOCs such as acetaldehyde are known to be taken up by stomata (Rottenberger et al., 2004), although they can also adsorb to cuticular waxes. 

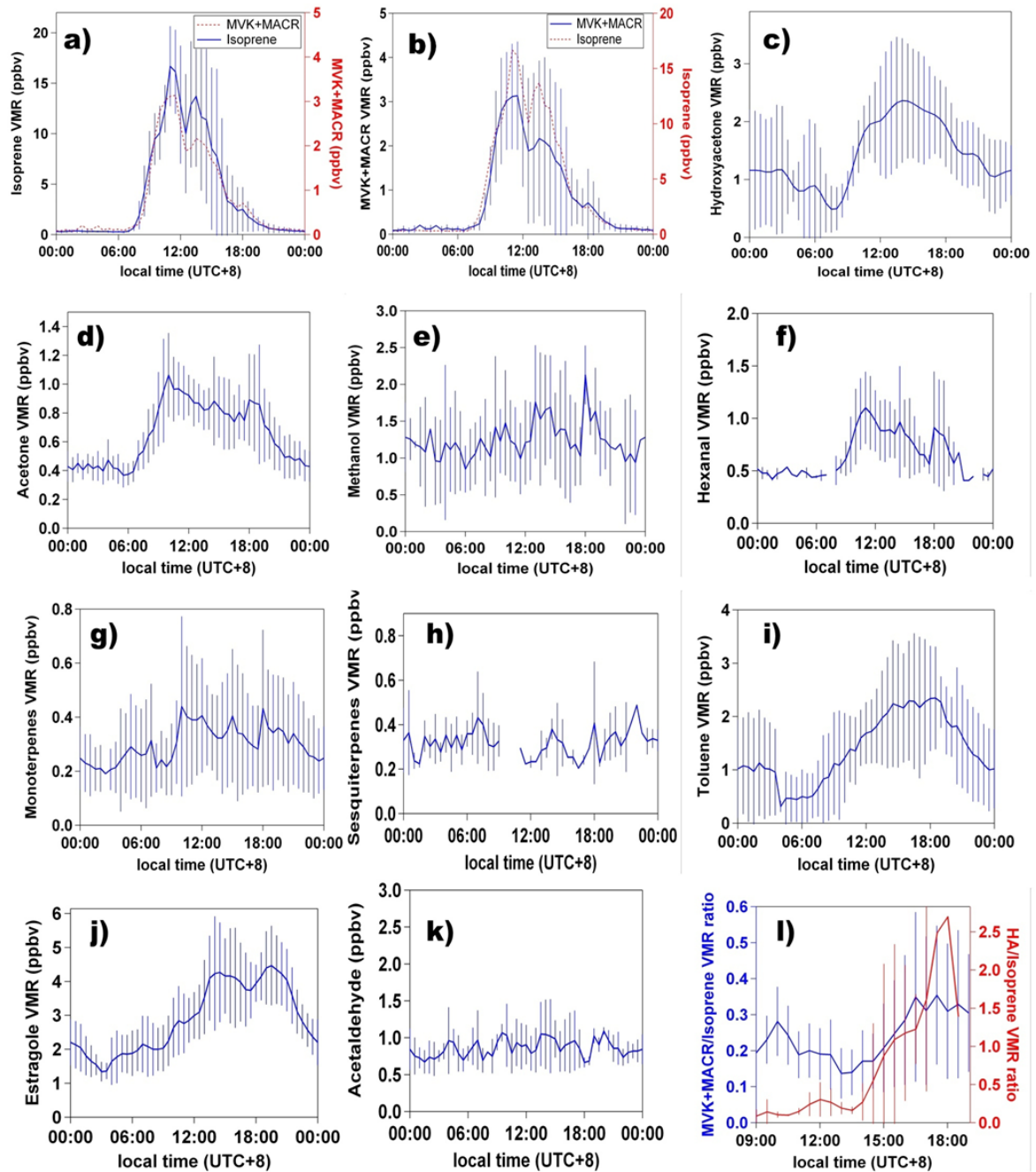

Fig. 3. Daily average diurnal mixing ratios of dominant VOCs (a-k) at the oil palm plantation; ratios of isoprene oxidation products (1). Error bars denote day-to-day variability (1 standard deviation).

\subsubsection{Estragole $\left(m / z^{+} 149\right)$}

Estragole (methyl chavicol) emissions from the oilpalm canopy were described in detail in Misztal et al. (2010). Although the palm fronds were probably responsible for the majority of VOC emissions, the flowers (thousands on one inflorescence) release estragole with a lag time of a few hours relative to temperature and PAR (Misztal et al., 2010). Due to its relatively short lifetime ( $1 \mathrm{~h}$; Bouvier-Brown et al., 2009) substantial emissions of estragole may make a significant contribution to regional photochemistry. Estragole mixing ratios were $3.0 \mathrm{ppbv}$ in the middle of the day but increased further later in the day (3.8 ppbv) and in the evening $(4.5 \mathrm{ppbv})$ which could be the effect of the potential thermogenesis of the flowers and accumulation in the shallow boundary layer. Estragole is important for the oil palm industry as it attracts the pollinating weevil (Hussein et al., 1989) enhancing crop yields.

\subsubsection{Hydroxyacetone (HA) $\left(m / z^{+} 75\right)$}

Another important oxidation product of isoprene is hydroxyacetone (HA), which is thought to derive mainly from MACR (see Fig. 6), and whose presence was reflected in the $m / z 75$ signal. Recently, Paulot et al. (2009) proposed the mechanism of hydroxyacetone formation directly from isoprene. Although attribution of this ion channel to HA has been recently reported as reliable (Karl et al., 2009), it is likely that this $\mathrm{m} / \mathrm{z}$ could also receive interferences from propionic acid and/or biogenic esters (such as methyl acetate and propionates), some of which are known kairomones (i.e., signalling chemicals that produce responses between species) of the oil palm weevil (Gries et al., 1994), and so may have been present in the air. This could lead to an overestimation of the HA to isoprene ratio, which was 0.1 in the morning, 0.2 during midday and sharply increasing in the afternoon to about 1 , when isoprene emissions were small. However, 


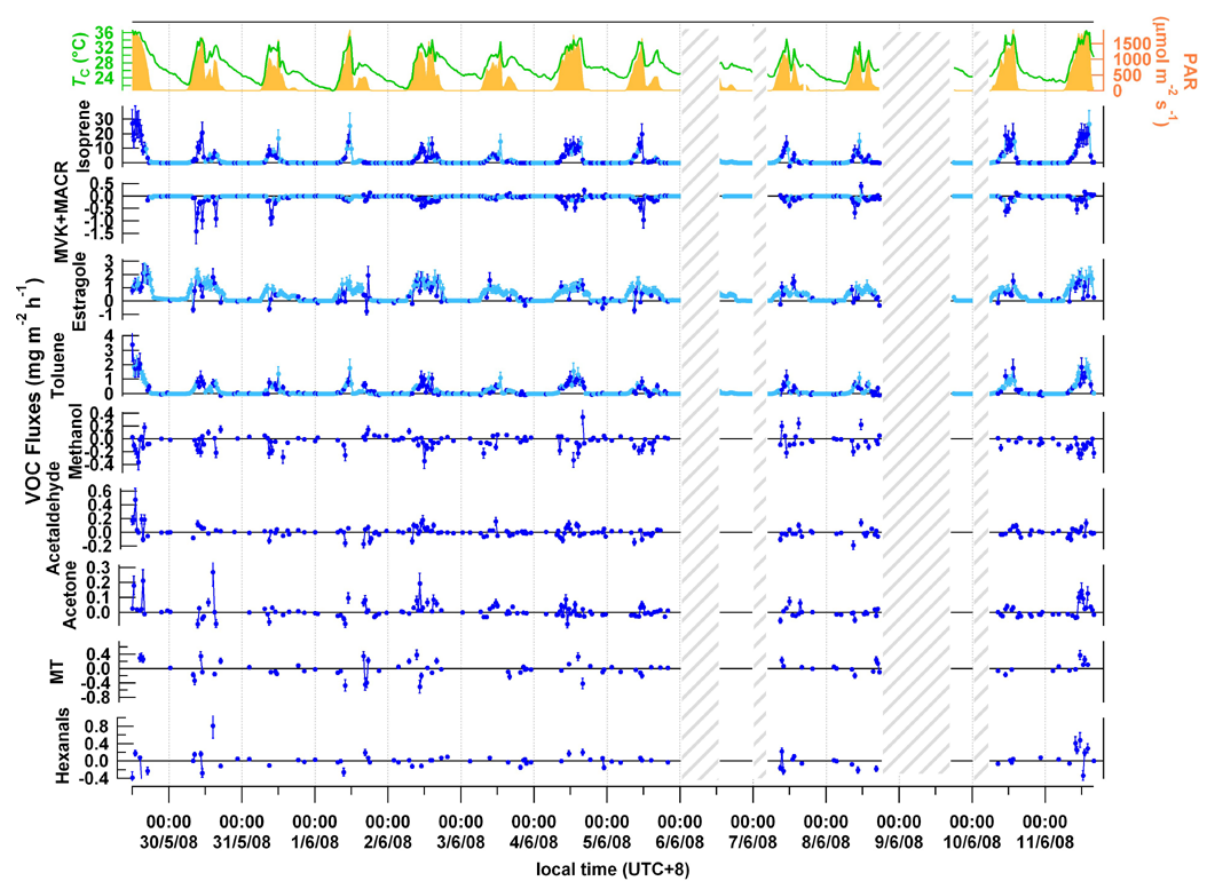

Fig. 4. Measured (dark blue) and modelled (light blue; see Sect. 3.5) flux time series of targeted VOCs. Crosshatched zones correspond to power interruptions.

HA has a relatively long atmospheric lifetime of 4 days with respect to OH (Orlando et al., 1999), so can potentially accumulate in the shallow boundary layer after its collapse in the evening.

Due to the limited number of compounds which could be measured in the eddy covariance mode, $\mathrm{m} / \mathrm{z}, 75$ was not included in the flux mode, so only the results for VMRs, which were derived from the hourly $5 \mathrm{~min}$ scan data, are presented (Table 3). It should be noted that $5 \mathrm{~min}$. correspond to 3 scan cycles across the full $\mathrm{m} / \mathrm{z}$ range, giving altogether $1.5 \mathrm{~s}$ $(3 \times 0.5 \mathrm{~s})$ per each $\mathrm{m} / \mathrm{zin}$ an hour, thus offering only a small measurement duty cycle compared to those compounds included in the flux mode. The major source of HA is the oxidation of MACR (Carter and Atkinson, 1996). However, the correlation with MVK + MACR mixing ratios was quite weak $\left(r^{2}=0.4\right.$, slope $\left.0.4 \pm 0.1\right)$ so it is highly probable that this $m / z$ ion channel received contributions from the other compounds mentioned above. Karl et al. (2009) found ten times higher $\mathrm{HA} /(\mathrm{MVK}+\mathrm{MACR})$ ratios than predicted from the MACR $\rightarrow$ HA reaction scheme (Fig. 6). They suggested another source of HA within the isoprene oxidation scheme but faster than the MACR production, or other sources such as the oxidation of peroxides or from oxidation of acetone. The mechanism of isoprene photo-degradation is quite uncertain at high VOC/NOx ratios, such as those measured at the oil palm plantation (see Stone et al., 2011, for a discussion of the difficulties of modelling aircraft-measured atmospheric composition over rainforest and oil palm landscapes due to uncertainties in the $\mathrm{OH}$-isoprene chemistry).

\subsubsection{Toluene $\left(m / z^{+} 93\right)$}

Emissions of aromatic compounds from vegetation are currently not well understood or quantified. Very high signals (corresponding to $1.7 \mathrm{ppbv}$ ) were detected at $\mathrm{m} / \mathrm{z}$ 93, typically assigned to toluene. Clear fluxes, diurnal patterns and confirmed lack of anthropogenic contributions suggested a biogenic source. Biogenic toluene emissions have been reported by Heiden et al. (1999) from sunflowers and pines, and, more recently, by White et al. (2009) from alfalfa as well as by Jardine et al. (2010) from creosotebush, although the absolute mixing ratios were smaller in all three studies than encountered at the oil palm plantation. Toluene is known to be emitted by flowers of many other species such as Anthurium (Kuanprasert et al., 1998), Ophrys orchids (Borgkarlson et al., 1985, 1987), Prunus trees (Baraldi et al., 1999) and kiwi fruit (Tatsuka et al., 1990). Hadacek and Weber (2002) found toluene-rich scents (referred to as "medicinal odour") in Sauromatum guttatum belonging to the same family (Arecaceae) as oil palm. These scents were observed to be attractants of tephritid flies.

However, toluene has not yet been reported as a constituent of oil palm emissions. In various measurement campaigns conducted in conjunction with GC-MS, the $m / z 93$ channel was validated as toluene with good agreement. The only other significant contribution to $\mathrm{m} / \mathrm{z} 93$ found so far has been from p-cymene (Maleknia et al., 2007; Tani et al., 2003). Monoterpene fragmentation could also contribute to this $\mathrm{m} / \mathrm{z}$ but the relative abundance at this $\mathrm{m} / \mathrm{z} 93$ is only $1 \%$ 

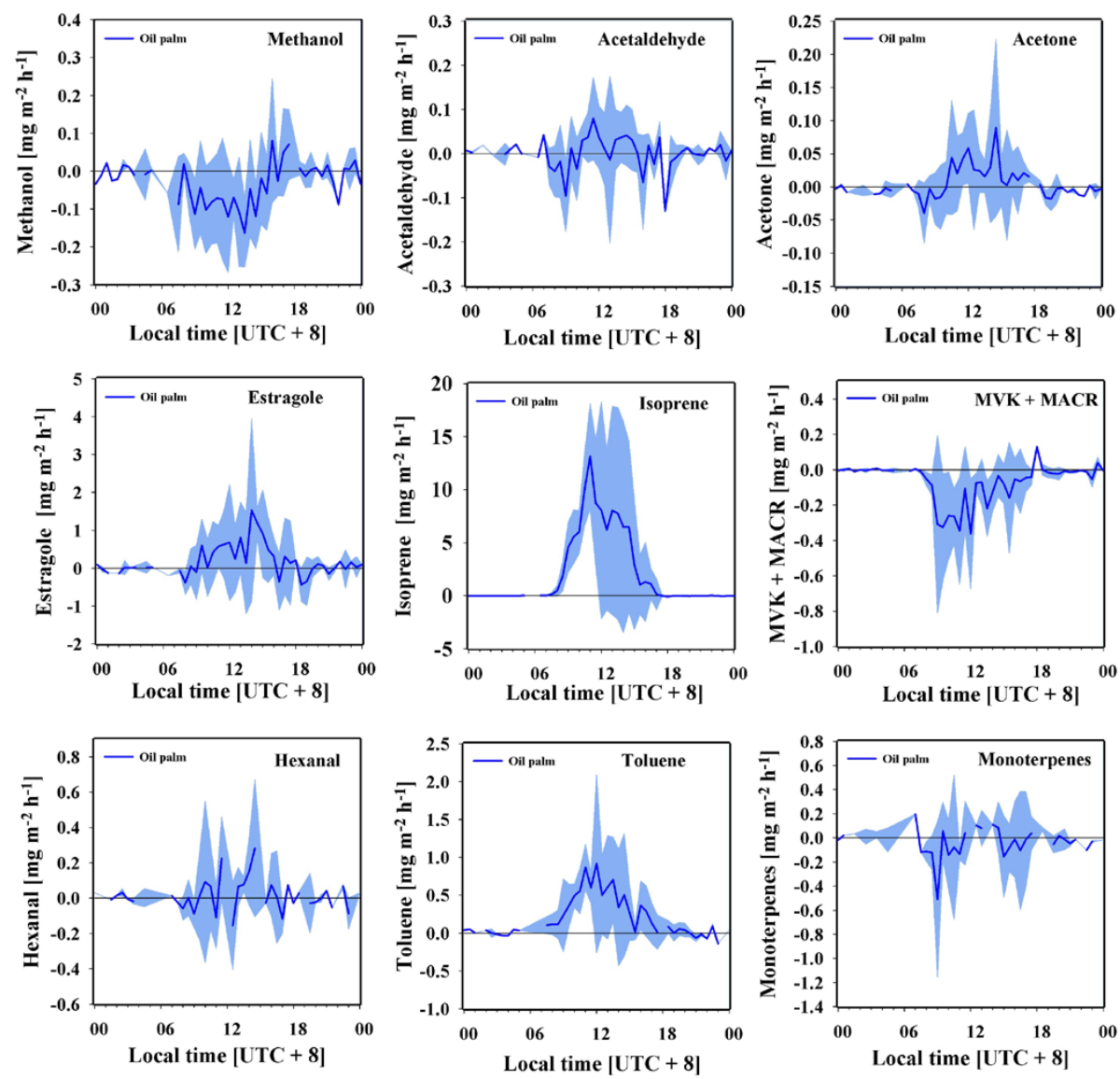

Fig. 5. Average diurnal cycles of VOC fluxes with one standard deviation (shaded).

or less of the relative abundance (Tani et al., 2003, 2004; Ambrose et al., 2010) irrespective of the $E / N$ values commonly used. Although other contributions at $\mathrm{m} / \mathrm{z} 93$ cannot be excluded, the known interferences from $p$-cymene, hydrated hydroxyacetone, monoterpenes or chloroacetone were tested and found unlikely. Initially it was hypothesised that the emissions of toluene were related to a fungus which is commonly found in a symbiosis with the fronds (as pinkish spots) and small levels of toluene were indeed found in some infected fronds during enclosure studies. However, much higher levels were subsequently found in the flower enclosures which were undertaken for the purpose of estragole source screening (Misztal et al., 2010). The toluene flux showed good correlations with temperature $\left(r^{2}=0.77\right)$ and PAR $\left(r^{2}=0.69\right)$; the exponential relationships were not as good as those for isoprene flux. A correlation with PAR does not necessarily imply that toluene emission is PAR dependent as temperature and PAR variables are strongly autocorrelated.

Toluene was only detected in the adsorbent tubes sampled from male inflorescences although its detection may have been compromised by the highly abundant estragole from female inflorescences which saturated the GC-MS de- tector. However, it was not detected in any of the femaleflower tubes (run in a female-male-female-male sequence) nor in any other tube from the same batch (e.g. those used in a parallel study at the rainforest). Another observation is that the diurnal pattern of toluene is shifted towards later in the day (Fig. 3) as is the case for the florally-emitted estragole. As the winds were commonly blowing from the $\mathrm{S}$ no evident contributions were identified from either the oil palm mill or residential areas, although aircraft measurements over oil palm (Hewitt et al., 2009) noted methanol spikes over a plume originating from the oil palm processing plants (mills). Methanol concentrations, however, were very low at this site. In addition, acetonitrile, detected at $\mathrm{m} / \mathrm{z} 42$, lacked spike features typical for anthropogenic occurrences and no $\mathrm{m} / \mathrm{z} 79$ signal typical for benzene was recorded. Consequently flowers, which are pollinated all year round, seem to be the major source of toluene from oil palm.

\subsubsection{Methanol $\left(m / z^{+} 33\right)$}

Methanol is an oxygenated VOC, which is of interest for atmospheric chemistry (Tie et al., 2003) and has been widely studied in various environments (Brunner et al., 2007; Custer 


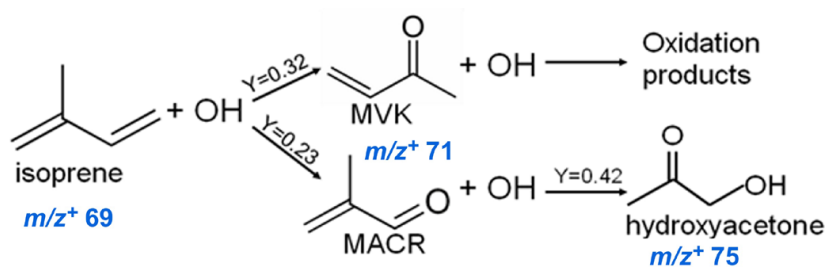

Fig. 6. Basic schematic of isoprene photooxidation with branching ratios (adapted from Karl et al., 2009).

and Schade, 2007; Seco et al., 2007; Sinha et al., 2007). It is a very important alcohol because of its high impact on tropospheric oxidation (Tie et al., 2003). Due to an unexpectedly high background encountered at this $\mathrm{m} / \mathrm{z}$ value less than a half of the data unambiguously exceeded the higher than normal detection limit (see Sect. 3.1, SI-4 and SI-6). This did not seem to be related to contribution from isotopic $\mathrm{O}_{2}^{+}$ which was calculated to be less than $1 \%$ of the total $\mathrm{m} / \mathrm{z} 33$ signal. As gathered from the lack of correlation with $\mathrm{m} / \mathrm{z}, 37$ $\left(r^{2}<0.01\right)$, the methanol signal was not humidity dependent at oil palm, and thus in the light of Ruuskanen et al. (2011) methanol deposition could not be subject to an artefact of water-flux dependent $\mathrm{O}_{2}^{+}$isotope signal loss. Methanol mixing ratios exceeding LOD were well correlated with friction velocity during the day and the vDEC flux was usually negative, making methanol the most strongly depositing compound after MVK + MACR. Owing to its relatively high Henry's law constant, methanol can be removed from the atmosphere by precipitation and dry deposition to wet surfaces (Crutzen and Lawrence, 2000; Schade and Goldstein, 2006). However, the diurnal trend in methanol mixing ratios did not seem affected by midday rain episodes. Although soil is a known source of methanol (Schade and Custer, 2004), there is also a growing evidence that soil can drive deposition of methanol and other oxygenated VOCs (Asensio et al., 2007). Previous studies have found the net flux of methanol to be bi-directional, dominated by net emission with only transient deposition events, but the high humidity encountered in Borneo could be at least an indirect factor in the net deposition observed here. Our findings at the rainforest (Langford et al., 2010) also indicated net deposition of methanol. It is not known whether the sink for the downward flux was the leaf surface (wet or otherwise, and presence of epiphytes), the stomata, or the soil. Possible primary sources of methanol at the oil palm plantation include methane oxidation higher in the troposphere, pectin decomposition from senescing biomass (Fall, 2003) or pectin demethylation during leaf growth or stress (Davison et al., 2009; Folkers et al., 2008) which could be responsible for the exchange in the opposite direction.

\subsubsection{Acetaldehyde $\left(m / z^{+} 45\right)$}

According to recent 3-D modelling (GEOS-Chem) constrained by in situ and satellite observations, the largest acetaldehyde source in the atmosphere is from hydrocarbon secondary oxidation $\left(128 \mathrm{Tg} \mathrm{yr}^{-1}\right)$ with only $23 \mathrm{Tg} \mathrm{yr}^{-1}$ emitted directly from the biosphere including emission from decaying plants (Millet et al., 2010). In plants acetaldehyde has been shown to derive from ethanol fermentation under anoxic conditions in roots and leaves (Jardine et al., 2008; Winters et al., 2009) with much enhanced emissions after anoxic and wounding stress (Jardine et al., 2009), the latter probably resulting from fatty acid peroxidation by accumulated reactive oxygen species. The exchange of acetaldehyde is bidirectional because it can be taken up and consumed metabolically (Fall, 2003). However, it is suspected that photolysis of MVK from isoprene oxidation is a significant source of acetaldehyde in high isoprene environments (Atkinson et al., 2006). Other potential sources are propene degradation and the ozonolysis of isoprene (Taraborrelli et al., 2009). Millet et al. (2010) reported that the total acetaldehyde yield from isoprene, depending on the $\mathrm{NO}_{\mathrm{x}}$ level, is $1.9 \%-2.5 \%$ in GEOS-Chem, $4.7 \%-4.3 \%$ in MCMv3.1 and estimated at $2 \%$ by $3-\mathrm{D}$ modelling using the Mainz Isoprene Mechanism 2 (MIM2) (Taraborrelli et al., 2009).

At the plantation, acetaldehyde constituted $4 \%$ of total observed VOC mixing ratios and only $0.2 \%$ of the VOC flux. The elevated LOD for this compound yielded $57 \%$ of valid mixing ratio data. Although acetaldehyde was found to be the main compound detected at $m / z, 45$ there was not a uniformly good agreement with GC-MS. Potential artefacts including acetaldehyde generated from ozone and inlet materials have been reported (Northway et al., 2004), yet in our study there was no significant correlation between the mixing ratio of acetaldehyde and ozone, whose concentration was low (6 ppb), or with any other VOC. The mixing ratio lacked a clear diurnal trend (Fig. 3k) although in the full time series periods of correlation with $u_{*}$ are evident and the data had a clearly lognormal distribution (see Supplement).

However, a clearer trend was apparent in the fluxes (Fig. 5i) with prevailing periods of emissions, and with deposition periods in the morning or evening or around the rain episodes at noon time. The lack of structure in the mixing ratios, but a small positive flux, could suggest acetaldehyde flux originates from ethanol oxidation under the anaerobic soil conditions (soil-moisture dependent) with periods of deposition of photochemically formed acetaldehyde. It is also possible that the mixed flux derived from a compensation point process with the plants themselves (Jardine et al., 2009).

\subsubsection{Acetone $\left(m / z^{+} 59\right)$}

Acetone has been shown to be reliably detected by PTRMS at $m / z 59$ with a minor (up to $10 \%$ ) contribution from 
propanal (de Gouw, 2007). Potentially, glyoxal could be detected at this $\mathrm{m} / \mathrm{z}$ but its detection would require an aerosolcapturing inlet (Hellén et al., 2008). Acetone is regarded as a dominant VOC in the atmosphere (Singh et al., 1994) with the major source being the oxidation of VOC precursors. Field campaigns have reported elevated acetone concentrations above various vegetation types (Karl et al., 2005; Murphy et al., 2010; Warneke, 2002) and aircraft PTR-MS measurements showed particularly elevated acetone abundances above tropical rainforests (Pöschl et al., 2001; Karl et al., 2004). Among other sources are direct emissions from plants, biomass burning and decomposing biomass, and soil (Fall, 2003; Schade and Custer, 2004). Acetone mixing ratios were correlated with canopy temperature $\left(r^{2}=0.55\right)$, PAR $\left(r^{2}=0.30\right)$ and with MVK + MACR $\left(r^{2}=0.56\right)$ and isoprene mixing ratios $\left(r^{2}=0.55\right)$, although surprisingly the highest degree of correlation $\left(r^{2}=0.65\right)$ was obtained with hexanals $(\mathrm{m} / \mathrm{z}$ 83; Sect. 3.3.10), which are regarded to be wounding stress compounds. Acetone has not yet been reported explicitly as a stress compound, but there have been studies which indirectly related acetone to wounding (Custer and Schade, 2007), or found correlations between acetone and hexanal mixing ratios. For example, Davison et al. (2008) reported a high correlation between the fluxes of acetone and hexanals $\left(r^{2}=0.73\right)$ from grassland, after cutting, which was the second highest correlation after that of hexanals with hexenals. Similarity between the fluxes of acetone and hexanals at the plantation was poor, but this could also be due to differences in the deposition of the compounds. Acetone has a relatively long lifetime and its relatively high mixing ratios may not always be the result of a high net surface flux (Karl et al., 2004) because of the acetone concentration footprint being much larger than that of the flux. The 95th percentile value for acetone flux was only $0.10 \mathrm{mg} \mathrm{m}^{-2} \mathrm{~h}^{1}$, and the mean value was 0.012 which was very similar to the values obtained at the rainforest, of $0.12 \mathrm{mg} \mathrm{m}^{-2} \mathrm{~h}^{-1}$ and $0.012 \mathrm{mg} \mathrm{m}^{-2} \mathrm{~h}^{-1}$, respectively (Langford et al., 2010). The mixing ratio agrees well with the data from the GABRIEL 2005 campaign above the northern Amazonian rainforest, but the estimated acetone fluxes of $0.35 \mathrm{mg} \mathrm{m}^{-2} \mathrm{~h}^{-1}$ (Eerdekens et al., 2009) seem to have been a factor of three larger than in Borneo.

\subsubsection{Monoterpenes $\left(m / z^{+} \mathbf{8 1}, 137\right)$}

Monoterpenes were measured in the flux mode at $m / z 81$ and $m / z$ 137. Normally a sum of the signals at these $m / z$ ratios is used for quantification of total monoterpenes in order to account for variabilities in the relative proportion between $\mathrm{m} / \mathrm{z} 81$ and $\mathrm{m} / \mathrm{z} 137$ signals at variable humidity (Tani et al., 2003). High humidity can have an impact on the sensitivity (Tani et al., 2004), which was much better at $m / z, 81$ than at $m / z$ 137. Therefore both ions were calibrated separately, but the signals were not merged in order to avoid introducing noise from the less sensitive channel. Application of the statistical methods presented in Sect. 3.1 and SI-4 yielded good agreement between the mixing ratios of total monoterpenes derived from either $\mathrm{m} / \mathrm{z}$. However, only $45 \%$ of the mixing ratios exceeded the LOD for $m / z, 81$, and the rest was filled with half the LOD value for the purpose of producing an unbiased mean. Thus the mean mixing ratio for these oil palm data was $0.33 \mathrm{ppbv}$ which is higher than a value of $0.24 \mathrm{ppbv}$ at the rainforest, although much lower than for isoprene. The vDEC-derived value of $0.33 \mathrm{ppbv}$ is higher than suggested by results from leaf enclosure measurements (Owen et al., 2011). It is likely that ambient monoterpenes came from flowers as they were subsequently found in the flower enclosures. The ambient mixing ratios were not correlated with temperature $\left(r^{2}=0.10\right)$ or PAR $\left(r^{2}=0.07\right)$. As fluxes were derived on the more sensitive $m / z 81$ channel, one must bear in mind the potential of interferences from hexenals. However, the correlation of $\mathrm{m} / \mathrm{z} 81$ signal with $\mathrm{m} / \mathrm{z} 83$, corresponding to hexanals, was small $\left(r^{2}=0.16\right)$ suggesting that contributions from hexanals were limited, but there may exist other unknown contributions. The flux was dominated by deposition periods giving overall net deposition of $-0.026 \mathrm{mg} \mathrm{m}^{-2} \mathrm{~h}^{-1}$ which contrasts with the clear net average emission of $0.241 \mathrm{mg} \mathrm{m}^{-2} \mathrm{~h}^{-1}$ at the rainforest.

\subsubsection{Hexanals $\left(m / z^{+} 83\right)$}

Hexanals belong to a green leaf volatile class of compounds which are known to be emitted under stress (e.g. Davison et al., 2008; Filella et al., 2007; Karl et al., 2001). The VMRs were characterised by a clear diurnal trend and they were correlated with acetone $\left(r^{2}=0.66\right)$, and canopy temperature $\left(r^{2}=0.51\right)$ and weakly with PAR $\left(r^{2}=0.38\right)$. Interestingly $\log (m / z, 83)$ was correlated with MVK+MACR $\left(r^{2}=0.57\right)$ and with isoprene $\left(r^{2}=0.54\right)$, similar to what was earlier observed for acetone, suggesting that acetone and hexanals might be formed in the isoprene oxidation chain and/or may be emitted in response to the depositing oxidation products. Large amplitudes in temperature may trigger emissions of stress compounds, which can be sensed at ecosystem scale (Karl et al., 2008). Hexanal fluxes were generally small, $0.01 \mathrm{mg} \mathrm{m}^{-2} \mathrm{~h}^{-1}$ on average, without a clear diurnal trend, but with episodic emissions up to $0.8 \mathrm{mg} \mathrm{m}^{-2} \mathrm{~h}^{-1}$. These emissions may have been related to stress by a sudden temperature drop of more than $10^{\circ} \mathrm{C}$ following a mid-day rain episode during which occasional deposition events were common.

\subsubsection{Sesquiterpenes $\left(m / z^{+} 205\right)$}

Sesquiterpene quantification is of great interest to atmospheric chemistry due to their high reactivity and large aerosol formation potentials, and because of limited data due to analytical challenges to their reliable measurement. Despite the inclusion of $m / z 205$ in the vDEC flux mode with the hope of capturing emission episodes, the proportion of VMR 

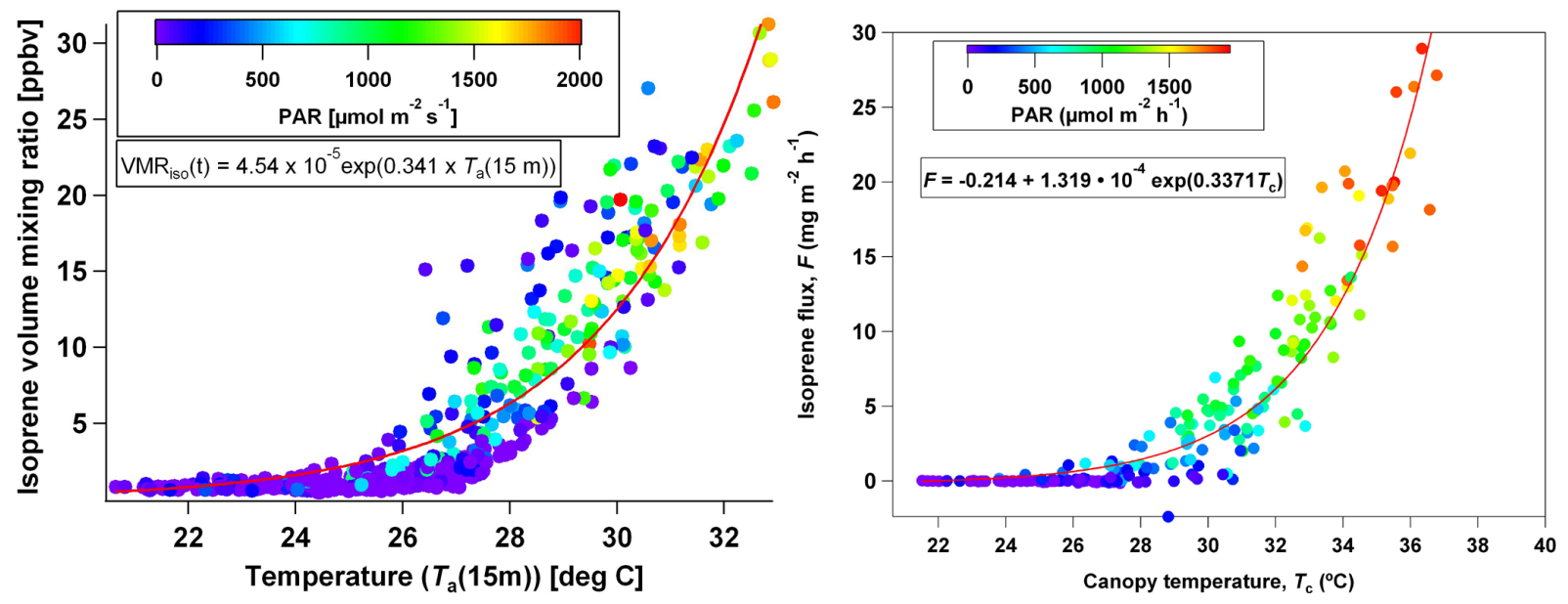

Fig. 7. Exponential relationships between temperature and isoprene mixing ratios (a), and fluxes (b), coloured according to magnitude of PAR.

Table 3. Comparison of parameters from G06 for isoprene, estragole, and toluene. Parameterisations of toluene are discussed in Sect. 3.5.2. Values for estragole were taken from Misztal et al. (2010).

\begin{tabular}{lrrrrr}
\hline G06 parameters & G06 original $\left(T_{\mathrm{c}}\right)$ & $\begin{array}{r}\text { Oil palm } \\
\text { optimised } \\
T_{\mathrm{a}}\left(z_{\mathrm{m}}\right)\end{array}$ & $\begin{array}{r}\text { Oil palm } \\
\text { optimised } \\
\left(T_{\mathrm{c}}\right)\end{array}$ & $\begin{array}{r}\text { Oil palm } \\
\text { optimised } \\
\left(T_{\mathrm{c}}\right)\end{array}$ & $\begin{array}{r}\text { Oil palm } \\
\text { optimised } \\
\left(T_{\mathrm{c}}\right)\end{array}$ \\
\hline Compound & Isoprene & Isoprene & Isoprene & Estragole & Toluene \\
\hline $\mathrm{C}_{T 1}$ & 95 & 130 & $174^{\mathrm{c}}$ & 131 & 95 \\
$\mathrm{C}_{T 2}$ & 230 & 235 & $2750^{\mathrm{c}}$ & 542 & 230 \\
$\mathrm{~b}_{1}$ & 0.004 & -0.00005 & 0.0007 & 0.031 & 0.0002 \\
$\mathrm{~b}_{2}$ & 0.0005 & -0.00003 & 0.00002 & 0.0030 & $-6 \times 10^{-6}$ \\
$\mathrm{~b}_{3}$ & 0.0468 & 0.0977 & 0.116 & 0.0453 & 0.174 \\
$\mathrm{~b}_{4}$ & 0.6 & 3.7 & 0.58 & -0.32 & 1.5 \\
$\mathrm{~b}_{5}$ & 2.034 & 2.608 & 3.790 & 1.812 & 2.161 \\
$\mathrm{~b}_{6}$ & 0.05 & 0.042 & -0.01 & -0.21 & 0.06 \\
$\mathrm{~T}_{b}$ & $313 \mathrm{~K}$ & $313 \mathrm{~K}$ & $317 \mathrm{~K}^{\mathrm{c}}$ & $307 \mathrm{~K}$ & $312 \mathrm{~K}$ \\
$\mathrm{P}_{0}$ & 200 (sun leaves) & 204 & 200 & 200 & 200 \\
& 50 (shaded leaves) & & & & \\
\hline BER & $7.8^{\mathrm{a}}\left(12.8^{\mathrm{b}}\right)$ & 18.8 & 22.8 & 0.80 & 0.53 \\
$\left(\mathrm{mg} \mathrm{m}^{-2} \mathrm{~h}^{-1}\right)$ & & & & & \\
\hline$R^{2}$ & 0.75 & 0.91 & 0.93 & 0.64 & 0.71 \\
vs. measured & & & & & \\
\hline
\end{tabular}

a derived from 1:1 slope of the fit with the measurement;

$\mathrm{b}$ derived from mean mid-day flux value (11:00 LT) over 12 days;

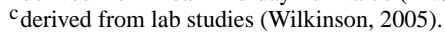

data above the LOD (0.2 ppbv) was relatively small (33\%). Measurement of low mixing ratios of sesquiterpenes is difficult because of humidity effects, inlet interactions, detection limits, and decreasing sensitivity at the higher end of the $\mathrm{m} / \mathrm{z}$ spectrum (Kim et al., 2009). In addition, sesquiterpene concentrations tend to be very small because their chemical life-time is so short that a large fraction is consumed between emission and reaching the measurement height (Kim et al., 2009). Therefore, the measured values should be regarded as a lower limit due to potential losses. Using the statistical method (Sect. 3.1 and SI-4) an average value for the mixing ratios was estimated at $0.13 \mathrm{ppbv}$ which is approximately 3 times less than the value for monoterpenes and 33 times less than the value for isoprene. Small emission 


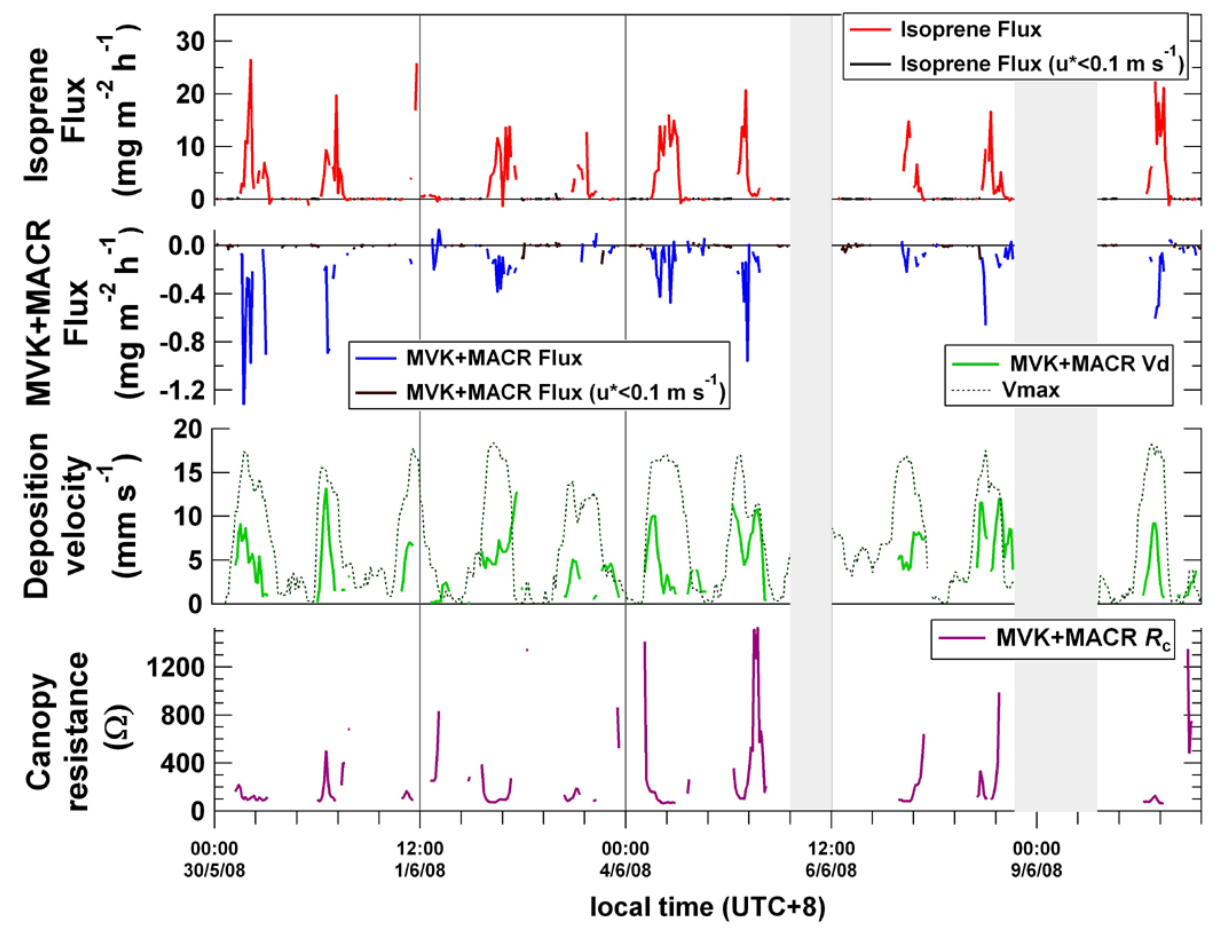

Fig. 8. MVK + MACR flux (blue), deposition velocity (green) in relation to maximum theoretical deposition velocity ( $\left.\mathrm{V}_{\max }\right)$ and the isoprene flux (red) for comparison.

of sesquiterpenes from fronds was also detected in the leaf enclosures (Owen et al., 2011) some of which could be associated with fungal algae growth. Due to flux quality assessment criteria the number of flux rejections was too high to include the fluxes in this work The uncertainty range for sesquiterpene VMRs was $\pm 150 \%$, which reflects the uncertainty in the reaction rate constant and transmission and estimated uncertainty of $\pm 50 \%$ due to sensitivity variation with relative humidity (Kim et al., 2009).

\subsection{Carbon loss}

Although the total VOC concentrations and fluxes reported in this study greatly exceed those measured above the rainforest (Langford et al., 2010), oil palms appear to be a much larger $\mathrm{CO}_{2}$ sink than the rainforest. The net photosynthetic carbon loss integrated over the day due to total VOC emission (Fig. 9), derived by dividing the total VOC flux of $128 \mathrm{mg} \mathrm{C} \mathrm{m}^{-2} \mathrm{~d}^{-1}$ by the total $\mathrm{CO}_{2}$ downward flux of $17100 \mathrm{mg} \mathrm{C} \mathrm{m}^{-2} \mathrm{~d}^{-1}$ (Skiba et al., 2011), amounted to $0.8 \%$ during daytime. This was double that found for the SE Asian rainforest (Langford et al., 2010), but still lower than the values reported for the Amazon rainforest (Karl et al., 2004; Kuhn et al., 2007). Although this value may seem relatively small, the implications of this portion of the carbon for atmospheric chemistry are huge due to its reactivity, aerosol formation potential, and influence on the oxidative capacity of the atmosphere.
The diurnal trend in the carbon loss is presented in Fig. 9a. It is noteworthy that the peak in both the total VOC flux and the $\mathrm{CO}_{2}$ uptake (Fig. 9b) generally occurred just prior to the onset of typical midday rain episodes.

\subsection{Use and parameter-fitting of flux algorithms}

\subsubsection{Isoprene emission (G06)}

Description of the G06 algorithm and the equation with labelled empirical parameters are presented in the Supplement (SI-8).

The original algorithm reproduces the emissions based on plant-specific basal emission rates, and regional PAR and temperature. The empirical parameters inside the activity factors generally do not need updating, as they have been optimised on a great number of measurements in different ecosystems. However, oil palm is a specific case due to unusual responses to light and temperature, and circadian rhythm of basal emission rates (Wilkinson et al., 2006). Canopy flux measurements allow us to determine best-fitting parameters for the algorithm and to derive the canopy basal emission rate. Although temperature and PAR responses and their biological functions are typically investigated in the leaf level studies, it is shown in Table 3 that the parameters obtained by fitting the algorithm to the measured fluxes can change some of the default values remarkably while not altering others. These changes lead to improvement in the 

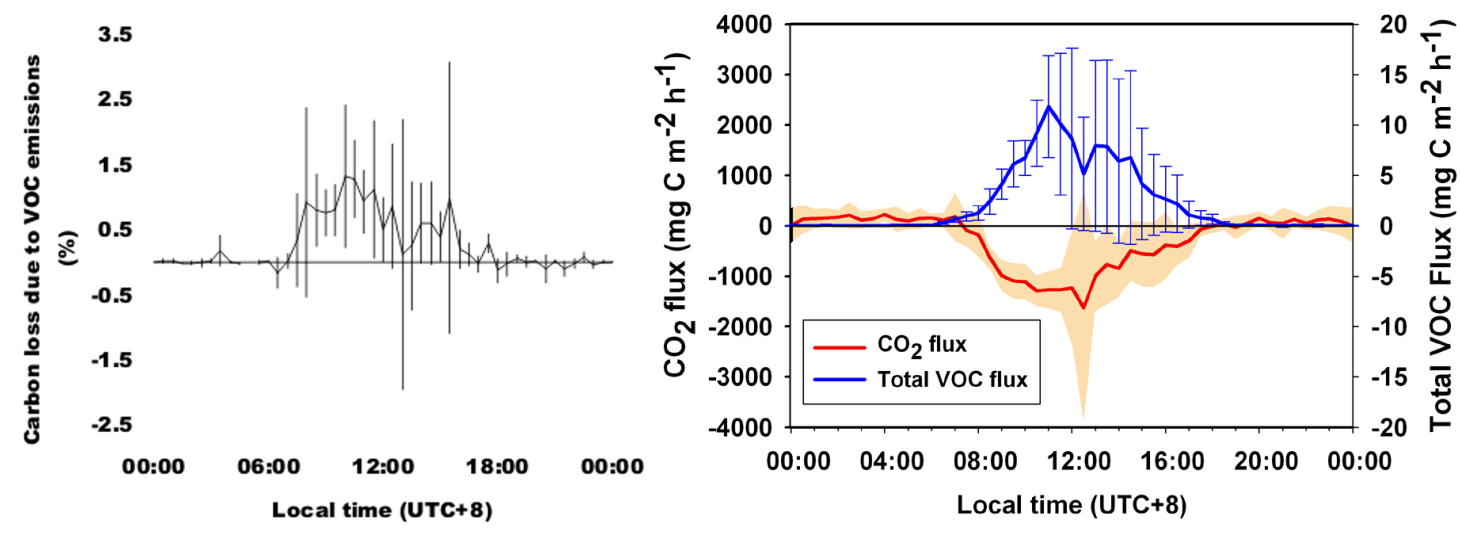

Fig. 9. (a) Net canopy carbon loss due to BVOC emissions at oil palm; (b) Diurnal trend of total VOC flux in comparison with CO2 flux. The datasets correspond to the same 2 week period.

overall fits with the measurement data even when the ambient temperature $T_{\mathrm{a}}(z)$ is used, which can be up to two degrees lower than the actual leaf temperature and therefore cause estimation of a smaller BER from the measurement. The $C_{\mathrm{T} 1}$ and $C_{\mathrm{T} 2}$ temperature response parameters and the maximal isoprene synthase temperature $\left(T_{\mathrm{b}}\right)$ have been previously measured in the laboratory by Wilkinson (2005). Clearly, the use of canopy temperature improves further the fit (SI-8). Which temperature is used impacts on the absolute value of BER that is required to achieve a 1:1 slope of the fit. It is therefore obvious that modellers who use leaf-level estimates of BERs should not use the available ambient temperature (e.g. from a weather station) without a conversion to the canopy temperature (see Sect. 2.3). There is currently no BER value for oil palm plant functional type (PFT) present in the MEGAN model (Guenther et al., 2006). If oil palm were classed as a crop the BER value from the fit with the non-parameterised G06 $\left(T_{\mathrm{c}}\right)$ model would be 8 times smaller than the default value of $1 \mathrm{mg} \mathrm{m}^{-2} \mathrm{~h}^{-1}$ but if it was classed as a broad-leaf tree (as in the "default" MEGAN model) then the value would fall well within the uncertainty span of the BER variabilities for the broad-leaf tree PFT but lower than for the tropical trees. Although the BER value of $8 \mathrm{mg} \mathrm{m}^{-2} \mathrm{~h}^{-1}$ would be sufficient for the original model to achieve a quantitative agreement in the total average flux, this value is still lower than the mid-day canopy average (10:00-14:00 LT) of $9.7 \mathrm{mg} \mathrm{m}^{-2} \mathrm{~h}^{-1}$ (see Table 2), much lower than the $18.8 \mathrm{mg} \mathrm{m}^{-2} \mathrm{~h}^{-1}$ value derived from the parameterised model (Table 3), the previously reported BER of $14.5 \mathrm{mg} \mathrm{m}^{-2} \mathrm{~h}^{-1}$ (Wilkinson et al., 2006), and the current value from leaf-level of $19.25 \mathrm{mg} \mathrm{m}^{-2} \mathrm{~h}^{-1}$ (Owen et al., 2011). This suggests that the parameterisation of the G06 model may be particularly important for the oil palm which is an exceptional case within the broad-leaf trees. A separate classification might be useful in the future for more specific representation of the expanding oil palm areas. The definition of BER is not yet fixed in modelling practice, as it is sometimes regarded as a single value from a leaf-level measurement under the normalised PAR $\left(1000 \mu \mathrm{mol} \mathrm{m}^{-2} \mathrm{~h}^{-1}\right)$ and temperature $\left(30^{\circ} \mathrm{C}\right)$ conditions, as the range of those values, or as the average of the representative values (Niinemets et al., 2010a, b, 2010; Guenther, 2010).

There is also a question whether the normalised values for PAR and temperature are optimal for all plants, since there might be saturation in some of them or an excessive value leading to a stress for a plant (Possell et al., 2010). Which BER value is best to use, what time of day is the most appropriate, or whether an average of measurements spanned over a day would be better is another question. This would be particularly relevant for plants whose BER undergoes circadian control. One possibility could be parameterisation of the algorithm for the use of the average BER from a daytime period (10:00-14:00 LT), which would lead to a larger BER of $12.8 \mathrm{mg} \mathrm{m}^{-2} \mathrm{~h}^{-1}$ (Table 3), and another is to use an average from midday (11:00 LT) when isoprene emissions were at their highest .

Finally, the parameterisation for oil palm reveals several significant differences from that for the rainforest reported by Langford et al. (2010), where most of the parameters did not change as a result of the parameterisation, which suggested that only the BERs required updating for the MEGAN model. The fit of the model to measurement was much better at the oil palm plantation than at the rainforest probably because of the lower sensor height, which results not only in a smaller footprint with less spatial variability in PAR, but also reduces the effects of storage and chemical conversion on the flux measurement. In addition, at the oil palm site, concentrations were larger, the sensitivity of the PTR-MS for isoprene was higher and the plant species composition was homogeneous for all wind directions. However, estimating the 
canopy temperature at the rainforest from the ambient temperature at $75 \mathrm{~m}$ and the heat fluxes improved the agreement significantly. It should be noted that the parameterisations disregard the canopy environmental model as they serve to illustrate the particular case of measurements close to the oilpalm canopies regarded as a "big leaf". Thus, the impact of the PAR attenuation throughout the canopy and its change throughout the day may affect the model fit for the forest more than for the oil palm plantation.

The original G06 algorithm for oil palm should be used either with the parameterisation presented here, appropriately collected hourly BERs, or at least by updating the BER used in MEGAN for oil palms with an adjusted BER of $8 \mathrm{mg} \mathrm{m}^{-2} \mathrm{~h}^{-1}$. For precise multi-layer modelling, an environmental model would need to be applied.

\subsubsection{Parameterisations for other VOCs}

The success of the BVOC emission model depends, among other things, on the dependence of emissions on environmental driving variables. For the temperature and PARdependent emissions, G06 seems to be a suitable model, which is relatively easy to parameterise. Individual parameters in that model have a biological meaning and have been derived in leaf-level measurement. Nevertheless, the parameterisation is here applied freely to investigate how well the model can be made to simulate the measurement and for application to gap-filling of the fluxes to achieve a higher representativeness of the reported fluxes. If the driving parameters were not associated with biological light and temperature responses then parameterisation would not succeed in producing a good fit. Only isoprene, estragole and toluene were found to be strongly temperature dependent, although the last two had a delayed response with temperature and PAR, most probably because the floral biochemistry and release are different from those of the leaves. It is also possible that toluene emissions might be mainly temperature dependent, but the relationship with temperature was not exponential as is typically the case for isoprene and monoterpene emissions. In Table 3 are listed the default parameters of G06 in comparison with the optimised parameters for each of the three emitted VOCs. Surprisingly the $C_{\mathrm{T} 1}$ and $C_{\mathrm{T} 2}$ values for toluene did not change in the parameterisation compared to the original parameters in MEGAN for isoprene. The $b_{1}$ and $b_{2}$ components of the activity factor associated with PAR response decreased by orders of magnitude to very small values but $b_{3}$ increased by a few factors. The components of temperaturerelated activity factors increased relatively weakly, 2.5 times in $b_{4}$, and by a tiny fraction in $\mathrm{b}_{5}$ and $\mathrm{b}_{6}$. The maximal enzyme temperature decreased by $1 \mathrm{~K}$. The modelled data were used for gap-filling, as shown in Fig. 4.

\subsection{Major differences between oilpalm plantation and rainforest}

Oil palm is a very homogenous monoculture whereas rainforest is extremely diverse and heterogeneous. The BVOC concentrations and fluxes for Borneo rainforest can be found in Langford et al. (2010). The general difference was a different mix and total quantity of BVOC over these types of ecosystem. The most striking difference was in the fluxes and concentrations of isoprene at the oil palm site which exceeded by 4 to 8 times the values at the rainforest. The other major feature of oil palms was a relatively high level of the floral pollinator attractant estragole which was not detected at the rainforest. On the other hand the fluxes of monoterpenes at the plantation were either very small or negative (deposition), whereas they were significant at the rainforest with total monoterpene to isoprene ratio of $0.24-0.27$, which is the second highest value reported so far from tropical regions. These major dissimilarities may give rise to different atmospheric chemistry, including oxidant chemistry (Hewitt et al., 2010) and aerosol composition.

\section{Conclusions}

These are the first direct canopy scale measurements of VOC mixing ratios and fluxes from an oil palm plantation, a rapidly expanding land-use type in SE Asia. In the varied VOC mix, isoprene constituted almost half of the mixing ratios by mass (as resolved by the PTR-MS) during the midday period (10:00-14:00 LT) with an average 13.1 ppbv. In the mid-day period the total flux of the emitted compounds was dominated by isoprene (84\%) at $9.7 \mathrm{mg} \mathrm{m}^{-2} \mathrm{~h}^{-1}$. The BER obtained from the fit of Guenther et al. (2006) activity factor and measurement was $7.8 \mathrm{mg} \mathrm{m}^{2} \mathrm{~h}^{-1}$, which is almost 8 times higher than the default value used in MEGAN for its generic agricultural crop land class. However, the BER value obtained from midday leaf level measurements and from the G06 algorithm parameterised to only midday fluxes were considerably higher.

The oxidation products of isoprene MVK + MACR exhibited clear deposition with the maximum deposition velocities reaching $1.5 \mathrm{~cm} \mathrm{~s}^{-1}$ and minimum canopy resistances $\left(R_{\mathrm{c}}\right)$ as low as $58 \mathrm{~s} \mathrm{~m}^{-1}$. This is consistent with other recent evidence (Karl et al., 2009, 2010) and may have implications for the effective aerosol yield of isoprene oxidation. In particular, MVK + MACR loss rates due to dry deposition may be larger in the field than in smog chambers (where surfaces are dry), thus resulting in an overestimation of isoprene aerosol yield under laboratory conditions.

Oil palm is not a significant monoterpene emitter, and although small amounts were detected, more precise studies are required to understand the mechanism of the small monoterpene emissions from oil palms. From the available data it appears that they might not be typically temperature 
and light dependent but might be more closely related to stress. Emissions could also be floral in origin or the apparent emissions may originate from outside of the footprint, fungi, algae, or understory plants.

Floral emissions from oil palms appear to be the largest sources of BVOCs, after the emission of isoprene from fronds. Oil palm inflorescences contain thousands of flowers which emit an anise-like odour dominated by estragole, whose canopy fluxes were the second highest $\left(0.81 \mathrm{mg} \mathrm{m}^{-2} \mathrm{~h}^{-1}\right)$, although its emission maximum was shifted towards later in the day compared to isoprene. Our findings suggest that the flowers may also be a source of toluene, emitted at a similar rate of $0.76 \mathrm{mg} \mathrm{m}^{-2} \mathrm{~h}^{-1}$. Toluene fluxes had a quadratic relationship with temperature, which could be reproduced by the G06 algorithm. Toluene was earlier found to be emitted from vegetation, but the emissions reported here would imply the largest biogenic source of toluene identified to date.

The projected expansion of oil palm areas may lead to tripling of these VOC emissions globally in the next 50 years. The findings suggest that much higher emissions of VOCs from oil palms than from a rainforest may have implications for land-use change on chemistry at the regional and in the long term also global scale. More studies over this important and expanding agro-ecosystem are required to measure the impact of these emissions on oxidative capacity of the atmosphere, peroxyradical mediated $\mathrm{OH}$ recycling and other climatological impacts.

\section{Supplementary material related to this article is available online at: http://www.atmos-chem-phys.net/11/8995/2011/ acp-11-8995-2011-supplement.pdf.}

Acknowledgements. This work was funded by the UK Natural Environment Research Council (NERC) through the projects "Aerosol Coupling in the Earth System" (ACES) and "Oxidant and Particle Photochemical Processes above a South-East Asian Tropical Rainforest" (OP3). Pawel Misztal was funded through a joint studentship at the University of Edinburgh School of Chemistry and Centre for Ecology \& Hydrology. We acknowledge the Sabahmas Plantations and in particular Foo Koh Kei, Yeap and Chang Sip Woon for access and site infrastructure (including housing, local transport and electricity). This is paper 520 of the Royal Society's South East Asia Rainforest Research Programme (SEARRP) and we are grateful to their staff at the Danum Valley field station (in particular to Glenn Reynolds, Jonny Larenus, and Alexander Karolus). In addition, we greatly thank Alex Guenther (NCAR), Peter Harley (NCAR), Chris Geron (EPA) and Reinhold Rasmussen (OHSU) for useful discussions in the field and providing valuable suggestions to the manuscript. We acknowledge the help of Mhairi Coyle and Carole Helfter (both $\mathrm{CEH}$ ) in processing the $\mathrm{CO}_{2}$ flux data.
Edited by: G. McFiggans

\section{References}

Ambrose, J. L., Haase, K., Russo, R. S., Zhou, Y., White, M. L., Frinak, E. K., Jordan, C., Mayne, H. R., Talbot, R., and Sive, B. C.: A comparison of GC-FID and PTR-MS toluene measurements in ambient air under conditions of enhanced monoterpene loading, Atmos. Meas. Tech., 3, 959-980, doi:10.5194/amt-3959-2010, 2010.

Asensio, D., Peñuelas, J., Filella, I., and Llusià, J.: Online screening of soil VOCs exchange responses to moisture, temperature and root presence, Plant Soil, 291, 249-261, doi:10.1007/s11104-006-9190-4, 2007.

Atkinson, R., Baulch, D. L., Cox, R. A., Crowley, J. N., Hampson, R. F., Hynes, R. G., Jenkin, M. E., Rossi, M. J., Troe, J., and IUPAC Subcommittee: Evaluated kinetic and photochemical data for atmospheric chemistry: Volume II - gas phase reactions of organic species, Atmos. Chem. Phys., 6, 3625-4055, doi:10.5194/acp-6-3625-2006, 2006.

Baraldi, R., Rapparini, F., Rossi, F., Latella, A., and Ciccioli, P.: Volatile organic compound emissions from flowers of the most occurring and economically important species of fruit trees, Phys. Chem. Earth Pt. B, 24, 729-732, 1999.

Behnke, K., Kaiser, A., Zimmer, I., Brüggemann, N., Janz, D., Polle, A., Hampp, R., Hänsch, R., Popko, J., Schmitt-Kopplin, P., Ehlting, B., Rennenberg, H., Barta, C., Loreto, F., and Schnitzler, J.-P.: RNAi-mediated suppression of isoprene emission in poplar transiently impacts phenolic metabolism under high temperature and high light intensities: a transcriptomic and metabolomic analysis, Plant Mol. Biol., 74, 61-75, doi:10.1007/s11103-0109654-z, 2010.

Borgkarlson, A. K., Bergstrom, G., and Groth, I.: Chemical basis for the relationship between Ophrys orchids and their pollinators .1. Volatile compounds of Ophrys-lutea and O-fusca as insect mimetic attractants excitants, Chem. Scripta, 25, 283-294, 1985.

Borgkarlson, A. K., Bergstrom, G., and Kullenberg, B.: Chemical basis for the relationship between Ophrys orchids and their pollinators 2. Volatile compounds of O-insectifera and $\mathrm{O}$-speculum as insect mimetic attractants excitants, Chem. Scripta, 27, 303-311, 1987.

Bouvier-Brown, N. C., Goldstein, A. H., Worton, D. R., Matross, D. M., Gilman, J. B., Kuster, W. C., Welsh-Bon, D., Warneke, C., de Gouw, J. A., Cahill, T. M., and Holzinger, R.: Methyl chavicol: characterization of its biogenic emission rate, abundance, and oxidation products in the atmosphere, Atmos. Chem. Phys., 9, 2061-2074, doi:10.5194/acp-9-2061-2009, 2009.

Brunner, A., Ammann, C., Neftel, A., and Spirig, C.: Methanol exchange between grassland and the atmosphere, Biogeosciences, 4, 395-410, 2007, http://www.biogeosciences.net/4/395/2007/.

Carter, W. P. L. and Atkinson, R.: Development and evaluation of a detailed mechanism for the atmospheric reactions of isoprene and NOx, Int. J. Chem. Kinet., 28, 497-530, 1996.

Caudill, S. P., Wong, L. Y., Turner, W. E., Lee, R., Henderson, A., and Patterson, D. G.: Percentile estimation 
using variable censored data, Chemosphere, 68, 169-180, doi:10.1016/j.chemosphere.2006.12.013, 2007.

Christian, T. J., Kleiss, B., Yokelson, R. J., Holzinger, R., Crutzen, P. J., Hao, W. M., Shirai, T., and Blake, D. R.: Comprehensive laboratory measurements of biomass-burning emissions: 2. First intercomparison of open-path FTIR, PTR-MS, and GC-ms/FID/ECD, J. Geophys. Res.-Atmos., 109(12), D02311 doi:10.1029/2003jd003874, 2004.

Clarke, J. U.: Evaluation of censored data methods to allow statistical comparisons among very small samples with below detection limit observations, Environ. Sci. Technol., 32, 177-183, 1998.

Crutzen, P. J. and Lawrence, M. G.: The Impact of Precipitation Scavenging on the Transport of Trace Gases: A 3Dimensional Model Sensitivity Study, J. Atmos. Chem., 37, 81112, doi:10.1023/a:1006322926426, 2000.

Custer, T. and Schade, G.: Methanol and acetaldehyde fluxes over ryegrass, Tellus B, 59, 673-684, doi:10.1111/j.16000889.2007.00294.x, 2007.

Davison, B., Brunner, A., Ammann, C., Spirig, C., Jocher, M., and Neftel, A.: Cut-induced VOC emissions from agricultural grasslands, Plant Biol., 10, 76-85, doi:10.1055/s-2007-965043, 2008.

Davison, B., Taipale, R., Langford, B., Misztal, P., Fares, S., Matteucci, G., Loreto, F., Cape, J. N., Rinne, J., and Hewitt, C. $\mathrm{N}$.: Concentrations and fluxes of biogenic volatile organic compounds above a Mediterranean macchia ecosystem in western Italy, Biogeosciences, 6, 1655-1670, 2009,

http://www.biogeosciences.net/6/1655/2009/.

de Gouw, J. and Warneke, C.: Measurements of Volatile Organic Compounds in the Earth's Atmosphere using Proton-TransferReaction Mass Spectrometry, Mass Spectrometry Reviews, 26, 223-257, doi:10.1002/mas.20119, 2007.

de Gouw, J., Warneke, C., Karl, T., Eerdekens, G., van der Veen, C., and Fall, R.: Sensitivity and specificity of atmospheric trace gas detection by proton-transfer-reaction mass spectrometry, Int. J. Mass Spectrom., 223-224, 365-382, 2003.

Eerdekens, G., Ganzeveld, L., Vilà -Guerau de Arellano, J., Klüpfel, T., Sinha, V., Yassaa, N., Williams, J., Harder, H., Kubistin, D., Martinez, M., and Lelieveld, J.: Flux estimates of isoprene, methanol and acetone from airborne PTR-MS measurements over the tropical rainforest during the GABRIEL 2005 campaign, Atmos. Chem. Phys., 9, 4207-4227, doi:10.5194/acp-9-42072009, 2009.

EPA: On-line Tools for Site Assessment Calculation: http://www.epa.gov/athens/learn2model/part-two/onsite/ estdiffusion-ext.htm, last access: 15 Aug 2009, 2007.

Fall, R.: Abundant Oxygenates in the Atmosphere: A Biochemical Perspective, Chemical Rev., 103, 4941-4952, doi:10.1021/cr0206521, 2003.

Fall, R. and Wildermuth, M. C.:Isoprene synthase: From biochemical mechanism to emission algorithm, J. Geophys. Res., 103(D19), 25599-25609, doi:10.1029/98JD00808, 1998.

FAOSTAT: Online Statistical Service. Item: Oil palm fruit; element: area harvested; year: 2007; country: World, South East Asia, Malaysia, Indonesia. http://faostat.fao.org, last access: April 2009, 2009.

Filella, I., Wilkinson, M. J., Llusia, J., Hewitt, C. N., and Penuelas, J.: Volatile organic compounds emissions in Norway spruce (Picea abies) in response to temperature changes, Physiol. Plantarum, 130, 58-66, doi:10.1111/j.1399-3054.2007.00881.x,
2007.

Folkers, A., Huve, K., Ammann, C., Dindorf, T., Kesselmeier, J., Kleist, E., Kuhn, U., Uerlings, R., and Wildt, J.: Methanol emissions from deciduous tree species: dependence on temperature and light intensity, Plant Biol., 10, 65-75, doi:10.1111/j.14388677.2007.00012.x, 2008.

Fowler, D., Nemitz, E., Misztal, P. K., Di Marco, C., Skiba, U., Ryder, J., Helfter, C., Cape, N., Owen, S., Dorsey, J., Gallagher, M. W., Coyle, M., Phillips, G., Davison, B., Langford, B., MacKenzie, A. R., Muller, J., Siong, J., Pyle, J. A., and Hewitt, C. N.: Effects of land use on trace gas emissions and deposition in Borneo: comparing atmosphere-surface exchange over oil palm plantations with a rainforest, Phil. Trans. Roy. Soc. Lond., invited submission for a special issue on Tropical forests, land-use change and climate, June, 2011.

Geron, C., Owen, S., Guenther, A., Greenberg, J., Rasmussen, R., Bai, J. H., Li, Q. J., and Baker, B.: Volatile organic compounds from vegetation in southern Yunnan Province, China: Emission rates and some potential regional implications, Atmos. Environ., 40, 1759-1773, doi:10.1016/j.atmosenv.2005.11.022, 2006.

Gries, G., Gries, R., Perez, A. L., Gonzales, L. M., Pierce, H. D., Cameron Oehlschlager, A., Rhainds, M., Zebeyou, M., and Kouame, B.: Ethyl propionate: Synergistic kairomone for african palm weevil, Rhynchophorus phoenicis L. (Coleoptera: Curculionidae), J. Chem. Ecol., 20, 889-897, doi:10.1007/bf02059585, 1994.

Guenther, A., Hewitt, C. N., Erickson, D., Fall, R., Geron, C., Graedel, T., Harley, P., Klinger, L., Lerdau, M., McKay, W. A., Pierce, T., Scholes, B., Steinbrecher, R., Tallamraju, R., Taylor, J., and Zimmerman, P.: A global-model o fnatural volatile organic-compound emissions, J. Geophys. Res.-Atmos., 100, 8873-8892, 1995.

Guenther, A., Karl, T., Harley, P., Wiedinmyer, C., Palmer, P. I., and Geron, C.: Estimates of global terrestrial isoprene emissions using MEGAN (Model of Emissions of Gases and Aerosols from Nature), Atmos. Chem. Phys., 6, 3181-3210, doi:10.5194/acp-63181-2006, 2006.

Hadacek, F. and Weber, M.: Club-Shaped Organs as Additional Osmophores within the Sauromatum Inflorescence: Odour Analysis, Ultrastructural Changes and Pollination Aspects, Plant Biol., 4, 367-383, doi:10.1055/s-2002-32335, 2002.

Heiden, A. C., Kobel, K., Komenda, M., Koppmann, R., Shao, M., and Wildt, J.: Toluene Emissions from Plants, Geophys. Res. Lett., 26, 1283-1286, 1999.

Hellén, H., Dommen, J., Metzger, A., Gascho, A., Duplissy, J., Tritscher, T., Prevot, A. S. H., and Baltensperger, U.: Using Proton Transfer Reaction Mass Spectrometry for Online Analysis of Secondary Organic Aerosols, Environ. Sci. Technol., 42, 7347 7353, doi:10.1021/es801279m, 2008.

Helsel, D. R.: Less than obvious - statistical treatment of data below the detection limit, Environ. Sci. Technol., 24, 1766-1774, 1990.

Hewitt, C. N., MacKenzie, A. R., Di Carlo, P., Di Marco, C. F., Dorsey, J. R., Evans, M., Fowler, D., Gallagher, M. W., Hopkins, J. R., Jones, C. E., Langford, B., Lee, J. D., Lewis, A. C., Lim, S. F., McQuaid, J., Misztal, P., Moller, S. J., Monks, P. S., Nemitz, E., Oram, D. E., Owen, S. M., Phillips, G. J., Pugh, T. A. M., Pyle, J. A., Reeves, C. E., Ryder, J., Siong, J., Skiba, U., and Stewart, D. J.: Nitrogen management is essential to prevent tropical oil palm plantations from causing 
ground-level ozone pollution, P. Natl. A Sci., 106, 18447-18451, doi:10.1073/pnas.0907541106, 2009.

Hewitt, C. N., Lee, J. D., MacKenzie, A. R., Barkley, M. P., Carslaw, N., Carver, G. D., Chappell, N. A., Coe, H., Collier, C., Commane, R., Davies, F., Davison, B., DiCarlo, P., Di Marco, C. F., Dorsey, J. R., Edwards, P. M., Evans, M. J., Fowler, D., Furneaux, K. L., Gallagher, M., Guenther, A., Heard, D. E., Helfter, C., Hopkins, J., Ingham, T., Irwin, M., Jones, C., Karunaharan, A., Langford, B., Lewis, A. C., Lim, S. F., MacDonald, S. M., Mahajan, A. S., Malpass, S., McFiggans, G., Mills, G., Misztal, P., Moller, S., Monks, P. S., Nemitz, E., Nicolas-Perea, V., Oetjen, H., Oram, D. E., Palmer, P. I., Phillips, G. J., Pike, R., Plane, J. M. C., Pugh, T., Pyle, J. A., Reeves, C. E., Robinson, N. H., Stewart, D., Stone, D., Whalley, L. K., and Yin, X.: Overview: oxidant and particle photochemical processes above a south-east Asian tropical rainforest (the OP3 project): introduction, rationale, location characteristics and tools, Atmos. Chem. Phys., 10, 169-199, doi:10.5194/acp-10169-2010, 2010.

Holzinger, R., Lee, A., Paw, K. T., and Goldstein, U. A. H.: Observations of oxidation products above a forest imply biogenic emissions of very reactive compounds, Atmos. Chem. Phys., 5, 67-75, doi:10.5194/acp-5-67-2005, 2005.

Hussein, M. Y., Lajis, N. H., Kinson, A., and Teo, C. B.: Laboratory and field evaluation on the attractancy of Elaeidobius kamerunicus Faust to 4-allylanisole, Porim Bull., 18, 20-26, 1989.

Jardine, K., Harley, P., Karl, T., Guenther, A., Lerdau, M., and Mak, J. E.: Plant physiological and environmental controls over the exchange of acetaldehyde between forest canopies and the atmosphere, Biogeosciences, 5, 1559-1572, 2008, http://www.biogeosciences.net/5/1559/2008/.

Jardine, K., Karl, T., Lerdau, M., Harley, P., Guenther, A., and Mak, J. E.: Carbon isotope analysis of acetaldehyde emitted from leaves following mechanical stress and anoxia, Plant Biol., 11, 591-597, doi:10.1111/j.1438-8677.2008.00155.x, 2009.

Jardine, K., Abrell, L., Kurc, S. A., Huxman, T., Ortega, J., and Guenther, A.: Volatile organic compound emissions from Larrea tridentata (creosotebush), Atmos. Chem. Phys., 10, 1219112206, doi:10.5194/acp-10-12191-2010, 2010.

Karl, T., Guenther, A., Lindinger, C., Jordan, A., Fall, R., and Lindinger, W.: Eddy covariance measurements of oxygenated volatile organic compound fluxes from crop harvesting using a redesigned proton-transfer-reaction mass spectrometer, J. Geophys. Res.-Atmos., 106, 24157-24167, 2001.

Karl, T., Potosnak, M., Guenther, A., Clark, D., Walker, J., Herrick, J. D., and Geron, C.: Exchange processes of volatile organic compounds above a tropical rain forest: Implications for modeling tropospheric chemistry above dense vegetation, J. Geophys. Res.-Atmos., 109, 24, D18306, doi:10.1029/2004jd004738, 2004.

Karl, T., Harley, P., Guenther, A., Rasmussen, R., Baker, B., Jardine, K., and Nemitz, E.: The bi-directional exchange of oxygenated VOCs between a loblolly pine (Pinus taeda) plantation and the atmosphere, Atmos. Chem. Phys., 5, 3015-3031, doi:10.5194/acp-5-3015-2005, 2005.

Karl, T., Guenther, A., Yokelson, R. J., Greenberg, J., Potosnak, M., Blake, D. R., and Artaxo, P.: The tropical forest and fire emissions experiment: Emission, chemistry, and transport of biogenic volatile organic compounds in the lower atmosphere over Amazonia, J. Geophys. Res.-Atmos., 112, 17, D18302, doi:10.1029/2007jd008539, 2007.

Karl, T., Guenther, A., Turnipseed, A., Patton, E. G., and Jardine, K.: Chemical sensing of plant stress at the ecosystem scale, Biogeosciences, 5, 1287-1294, 2008, http://www.biogeosciences.net/5/1287/2008/.

Karl, T., Guenther, A., Turnipseed, A., Tyndall, G., Artaxo, P., and Martin, S.: Rapid formation of isoprene photo-oxidation products observed in Amazonia, Atmos. Chem. Phys., 9, 7753-7767, doi:10.5194/acp-9-7753-2009, 2009.

Karl, T., Harley, P., Emmons, L., Thornton, B., Guenther, A., Basu, C., Turnipseed, A., and Jardine, K.: Efficient Atmospheric Cleansing of Oxidized Organic Trace Gases by Vegetation, Science, 330, 816-819, doi:10.1126/science.1192534, 2010.

Kim, S., Karl, T., Helmig, D., Daly, R., Rasmussen, R., and Guenther, A.: Measurement of atmospheric sesquiterpenes by proton transfer reaction-mass spectrometry (PTR-MS), Atmos. Meas. Tech., 2, 99-112, doi:10.5194/amt-2-99-2009, 2009.

Kuanprasert, N., Kuehnle, A. R., and Tang, C. S.: Floral fragrance compounds of some Anthurium (Araceae) species and hybrids, Phytochemistry, 49, 521-528, 1998.

Kuhn, U., Andreae, M. O., Ammann, C., Arajo, A. C., Brancaleoni, E., Ciccioli, P., Dindorf, T., Frattoni, M., Gatti, L. V., Ganzeveld, L., Kruijt, B., Lelieveld, J., Lloyd, J., Meixner, F. X., Nobre, A. D., Pschl, U., Spirig, C., Stefani, P., Thielmann, A., Valentini, R., and Kesselmeier, J.: Isoprene and monoterpene fluxes from Central Amazonian rainforest inferred from tower-based and airborne measurements, and implications on the atmospheric chemistry and the local carbon budget, Atmos. Chem. Phys., 7, 28552879, doi:10.5194/acp-7-2855-2007, 2007.

Kuster, W. C., Jobson, B. T., Karl, T., Riemer, D., Apel, E., Goldan, P. D., and Fehsenfeld, F. C.: Intercomparison of volatile organic carbon measurement techniques and data at la porte during the TexAQS2000 Air Quality Study, Environ. Sci. Technol., 38, 221228, doi:10.1021/es034710r, 2004.

Langford, B., Davison, B., Nemitz, E., and Hewitt, C. N.: Mixing ratios and eddy covariance flux measurements of volatile organic compounds from an urban canopy (Manchester, UK), Atmos. Chem. Phys., 9, 1971-1987, doi:10.5194/acp-9-1971-2009, 2009.

Langford, B., Nemitz, E., House, E., Phillips, G. J., Famulari, D., Davison, B., Hopkins, J. R., Lewis, A. C., and Hewitt, C. N.: Fluxes and concentrations of volatile organic compounds above central London, UK, Atmos. Chem. Phys., 10, 627-645, doi:10.5194/acp-10-627-2010, 2010.

Langford, B., Misztal, P. K., Nemitz, E., Davison, B., Helfter, C., Pugh, T. A. M., MacKenzie, A. R., Lim, S. F., and Hewitt, C. N.: Fluxes and concentrations of volatile organic compounds from a South-East Asian tropical rainforest, Atmos. Chem. Phys., 10, 8391-8412, doi:10.5194/acp-10-8391-2010, 2010.

Laothawornkitkul, J., Paul, N. D., Vickers, C. E., Possell, M., Taylor, J. E., Mullineaux, P. M., and Hewitt, C. N.: Isoprene emissions influence herbivore feeding decisions, Plant Cell Environ., 31, 1410-1415, 2008.

Loreto, F. and Schnitzler, J.-P.: Abiotic stresses and induced BVOCs, Trends Plant Sci., 15, 154-166, doi:10.1016/j.tplants.2009.12.006, 2010.

MacKenzie, A. R., Langford, B., Pugh, T. A. M., Robinson, N., Misztal, P. K., Heard, D. E., Lee, J. D., Lewis, A. C., Jones, C. 
E., Hopkins, J. R., Philips, G., Monks, P. S., Karunaharan, A., Hornsby, K. E., Nicolas-Perea, V., Coe, H., Whalley, L. K., Edwards, P. M., Evans, M. J., Stone, D., Ingham, T., Commane, R., Furneaux, K. L., McQuaid, J., Nemitz, E., Seng, Y. K., Fowler, D., Pyle, J. A., and Hewitt, C. N.: The atmospheric chemistry of trace gases and particulate matter emitted by different land uses in Borneo, Phil. Trans. Roy. Soc. Lond., invited submission for a special issue on Tropical forests, land-use change and climate, June, 2011.

Maleknia, S. D., Bell, T. L., and Adams, M. A.: PTR-MS analysis of reference and plant-emitted volatile organic compounds, Int. J. Mass Spectrom., 262, 203-210, 2007.

Millet, D. B., Guenther, A., Siegel, D. A., Nelson, N. B., Singh, H. B., de Gouw, J. A., Warneke, C., Williams, J., Eerdekens, G., Sinha, V., Karl, T., Flocke, F., Apel, E., Riemer, D. D., Palmer, P. I., and Barkley, M.: Global atmospheric budget of acetaldehyde: 3-D model analysis and constraints from in situ and satellite observations, Atmos. Chem. Phys., 10, 3405-3425, doi:10.5194/acp-10-3405-2010, 2010.

Misztal, P. K., Owen, S. M., Guenther, A. B., Rasmussen, R., Geron, C., Harley, P., Phillips, G. J., Ryan, A., Edwards, D. P., Hewitt, C. N., Nemitz, E., Siong, J., Heal, M. R., and Cape, J. N.: Large estragole fluxes from oil palms in Borneo, Atmos. Chem. Phys., 10, 4343-4358, doi:10.5194/acp-10-4343-2010, 2010.

Müller, M., Graus, M., Ruuskanen, T. M., Schnitzhofer, R., Bamberger, I., Kaser, L., Titzmann, T., Hörtnagl, L., Wohlfahrt, G., Karl, T., and Hansel, A.: First eddy covariance flux measurements by PTR-TOF, Atmos. Meas. Tech., 3, 387-395, doi:10.5194/amt-3-387-2010, 2010.

Murphy, J. G., Oram, D. E., and Reeves, C. E.: Measurements of volatile organic compounds over West Africa, Atmos. Chem. Phys., 10, 5281-5294, doi:10.5194/acp-10-5281-2010, 2010.

Nemitz, E., Dorsey, J. R., Flynn, M. J., Gallagher, M. W., Hensen, A., Erisman, J. W., Owen, S. M., Dämmgen, U., and Sutton, M. A.: Aerosol fluxes and particle growth above managed grassland, Biogeosciences, 6, 1627-1645, doi:10.5194/bg-6-16272009, 2009a.

Nemitz, E., Hargreaves, K. J., Neftel, A., Loubet, B., Cellier, P., Dorsey, J. R., Flynn, M., Hensen, A., Weidinger, T., Meszaros, R., Horvath, L., Dämmgen, U., Frühauf, C., Löpmeier, F. J., Gallagher, M. W., and Sutton, M. A.: Intercomparison and assessment of turbulent and physiological exchange parameters of grassland, Biogeosciences, 6, 1445-1466, 2009b, http://www.biogeosciences.net/6/1445/2009/.

Nemitz, E., Loubet, B., Lehmann, B. E., Cellier, P., Neftel, A., Jones, S. K., Hensen, A., Ihly, B., Tarakanov, S. V., and Sutton, M. A.: Turbulence characteristics in grassland canopies and implications for tracer transport, Biogeosciences, 6, 1519-1537, 2009c, http://www.biogeosciences.net/6/1519/2009/.

Niinemets, Ü., Monson, R. K., Arneth, A., Ciccioli, P., Kesselmeier, J., Kuhn, U., Noe, S. M., Peñuelas, J., and Staudt, M.: The leaflevel emission factor of volatile isoprenoids: caveats, model algorithms, response shapes and scaling, Biogeosciences, 7, 18091832, doi:10.5194/bg-7-1809-2010, 2010a.

Niinemets, Ü., Arneth, A., Kuhn, U., Monson, R. K., Peñuelas, J., and Staudt, M.: The emission factor of volatile isoprenoids: stress, acclimation, and developmental responses, Biogeosciences, 7, 2203-2223, doi:10.5194/bg-7-2203-2010,
2010 b.

Niinemets, Ü., Monson, R. K., Arneth, A., Ciccioli, P., Kesselmeier, J., Kuhn, U., Noe, S. M., Peñuelas, J., and Staudt, M.: The leaflevel emission factor of volatile isoprenoids: caveats, model algorithms, response shapes and scaling, Biogeosciences, 7, 18091832, doi:10.5194/bg-7-1809-2010, 2010.

Northway, M. J., de Gouw, J. A., Fahey, D. W., Gao, R. S., Warneke, C., Roberts, J. M., and Flocke, F.: Evaluation of the role of heterogeneous oxidation of alkenes in the detection of atmospheric acetaldehyde, Atmos. Environ., 38, 6017-6028, doi:10.1016/j.atmosenv.2004.06.039, 2004.

Orlando, J. J., Tyndall, G. S., Fracheboud, J.-M., Estupiñan, E. G., Haberkorn, S., and Zimmer, A.: The rate and mechanism of the gas-phase oxidation of hydroxyacetone, Atmos. Environ., 33, 1621-1629, 1999.

Owen, S. M. and Penuelas, J.: Opportunistic emissions of volatile isoprenoids, Trends Plant. Sci., 10, 420-426, 2005.

Owen, S. M., Wilkinson, M. J., Ryan, A., Linatoc, A., and Hewitt, C. N.: Variability in leaf level isoprene emission rate from oil palm, in preparation, 2011.

Paulot, F., Crounse, J. D., Kjaergaard, H. G., Kurten, A., St. Clair, J. M., Seinfeld, J. H., and Wennberg, P. O.: Unexpected Epoxide Formation in the Gas-Phase Photooxidation of Isoprene, Science, 325, 730-733, doi:10.1126/science.1172910, 2009.

Peñuelas, J. and Staudt, M.: BVOCs and global change, Trends Plant. Sci., 15, 133-144, doi:10.1016/j.tplants.2009.12.005, 2010.

Pinho, P. G., Pio, C. A., and Jenkin, M. E.: Evaluation of isoprene degradation in the detailed tropospheric chemical mechanism, MCM v3, using environmental chamber data, Atmos. Environ., 39, 1303-1322, doi:10.1016/j.atmosenv.2004.11.014, 2005.

Porter, P. S., Ward, R. C., and Bell, H. F.: The detection limit, Environ. Sci. Policy, 22, 856-861, 1988.

Pöschl, U., Williams, J., Hoor, P., Fischer, H., Crutzen, P. J., Warneke, C., Holzinger, R., Hansel, A., Jordan, A., Lindinger, W., Scheeren, H. A., Peters, W., and Lelieveld, J.: High Acetone Concentrations throughout the $0-12 \mathrm{~km}$ Altitude Range over the Tropical Rainforest in Surinam, J. Atmos. Chem., 38, 115-132, 2001.

Possell, M., Ryan, A., Vickers, C. E., Mullineaux, P. M., and Hewitt, C. N.: Effects of fosmidomycin on plant photosynthesis as measured by gas exchange and chlorophyll fluorescence, Photosynth. Res., 104, 49-59, doi:10.1007/s11120-009-9504-5, 2010.

Pugh, T. A. M., MacKenzie, A. R., Hewitt, C. N., Langford, B., Edwards, P. M., Furneaux, K. L., Heard, D. E., Hopkins, J. R., Jones, C. E., Karunaharan, A., Lee, J., Mills, G., Misztal, P., Moller, S., Monks, P. S., and Whalley, L. K.: Simulating atmospheric composition over a South-East Asian tropical rainforest: performance of a chemistry box model, Atmos. Chem. Phys., 10, 279-298, doi:10.5194/acp-10-279-2010, 2010.

Pyle, J. A., Warwick, N. J., Harris, N. R. P., Abas, M. R., Archibald, A., Ashfold, M. J., Ashworth, K., Barkley, M. P., Carver, G. D., Chance, K., Dorsey, J., Fowler, D., Gonzi, S., Gostlow, B., Hewitt, C. N., Kurosu, T. P., Lee, J. D., Langford, B., Mills, G., Möller, S., MacKenzie, A. R., Manning, A. J., Misztal, P. K., Nadzir, M. S. M., Nemitz, E., Newton, H., O’Brien, L. M., Ong, S., Oram, D., Palmer, P. I., Peng, L. K., Phang, S. M., Pike, R., Pugh, T. A. M., Rahman, N. A., Robinson, A. D., Sentian, J., Samah, A. A., Skiba, U., Ung, H. E., Yong, S. E., and Young, 
P.: The impact of local land surface changes in Borneo on atmospheric composition at wider spatial scales: coastal processes, land use change and air quality, Phil. Trans. Roy. Soc. Lond., invited submission for a special issue on Tropical forests, land-use change and climate, June, 2011.

Rinne, J., Taipale, R., Markkanen, T., Ruuskanen, T. M., Hellén, H., Kajos, M. K., Vesala, T., and Kulmala, M.: Hydrocarbon fluxes above a Scots pine forest canopy: measurements and modeling, Atmos. Chem. Phys., 7, 3361-3372, doi:10.5194/acp-73361-2007, 2007.

Robinson, N. H., Hamilton, J. F., Allan, J. D., Langford, B., Oram, D. E., Chen, Q., Docherty, K., Farmer, D. K., Jimenez, J. L., Ward, M. W., Hewitt, C. N., Barley, M. H., Jenkin, M. E., Rickard, A. R., Martin, S. T., McFiggans, G., and Coe, H.: Evidence for a significant proportion of Secondary Organic Aerosol from isoprene above a maritime tropical forest, Atmos. Chem. Phys., 11, 1039-1050, doi:10.5194/acp-11-1039-2011, 2011.

Rottenberger, S., Kuhn, U., Wolf, A., Schebeske, G., Oliva, S. T., Tavares, T. M., and Kesselmeier, J.: Exchange of short-chain aldehydes between Amazonian vegetation and the atmosphere, Ecol. Appl., 14, S247-S262, 2004.

Ruuskanen, T. M., Müller, M., Schnitzhofer, R., Karl, T., Graus, M., Bamberger, I., Hörtnagl, L., Brilli, F., Wohlfahrt, G., and Hansel, A.: Eddy covariance VOC emission and deposition fluxes above grassland using PTR-TOF, Atmos. Chem. Phys., 11, 611-625, doi:10.5194/acp-11-611-2011, 2011.

Ryder, J., Langford, B., Oram, D., Coyle, M., Phillips, G. J., Helfter, C., Misztal, P. K., Cape, J. N., and Nemitz, E.: Sources and sinks of biogenic volatile organic compounds inside a South-East Asian rainforest canopy, Atmos. Chem. Phys. Discuss., in preparation, 2011.

Schade, G. W., and Custer, T. G.: OVOC emissions from agricultural soil in northern Germany during the 2003 European heat wave, Atmos. Environ., 38, 6105-6114, doi:10.1016/j.atmosenv.2004.08.017, 2004.

Schade, G. W. and Goldstein, A. H.: Seasonal measurements of acetone and methanol: Abundances and implications for atmospheric budgets, Global Biogeochem. Cy., 20, GB1011, doi:10.1029/2005gb002566, 2006.

Seco, R., Penuelas, J., and Filella, I.: Short-chain oxygenated VOCs: Emission and uptake by plants and atmospheric sources, sinks, and concentrations, Atmos. Environ., 41, 2477-2499, 2007.

Sentian, J., MacKenzie, R. A., and Hewitt, C. N.: The regional biogenic emissions response to climate changes and ambient $\mathrm{CO}_{2}$ in Southeast Asia, International Journal of Climate Change: Impacts and Responses, 2, 125-142, 2010.

Singh, H. B., Ohara, D., Herlth, D., Sachse, W., Blake, D. R., Bradshaw, J. D., Kanakidou, M., and Crutzen, P. J.: Acetone in the atmosphere - distribution, sources and sinks, J. Geophys. Res.Atmos., 99, 1805-1819, 1994.

Singles, R., Sutton, M. A., and Weston, K. J.: A multi-layer model to describe the atmospheric transport and deposition of ammonia in Great Britain, Atmos. Environ., 32, 393-399, 1998.

Sinha, V., Williams, J., Meyerhöfer, M., Riebesell, U., Paulino, A. I., and Larsen, A.: Air-sea fluxes of methanol, acetone, acetaldehyde, isoprene and DMS from a Norwegian fjord following a phytoplankton bloom in a mesocosm experiment, Atmos. Chem. Phys., 7, 739-755, doi:10.5194/acp-7-739-2007, 2007.
Skiba, U. M., Siong, J., Helfter, C., Di Marco, C., Linatoc, A., Fowler, D., and Nemitz, E.: Greenhouse gas $\left(\mathrm{N}_{2} \mathrm{O}, \mathrm{CH}_{4}\right.$ and $\mathrm{CO}_{2}$ ) exchange with contrasting land uses in SE Asia, Atmos. Chem. Phys. Discuss., in preparation, 2011.

Stone, D., Evans, M. J., Edwards, P. M., Commane, R., Ingham, T., Rickard, A. R., Brookes, D. M., Hopkins, J., Leigh, R. J., Lewis, A. C., Monks, P. S., Oram, D., Reeves, C. E., Stewart, D., and Heard, D. E.: Isoprene oxidation mechanisms: measurements and modelling of $\mathrm{OH}$ and $\mathrm{HO}_{2}$ over a South-East Asian tropical rainforest during the OP3 field campaign, Atmos. Chem. Phys., 11, 6749-6771, doi:10.5194/acp-11-6749-2011, 2011.

Sutton, M. A., Burkhardt, J. K., Guerin, D., Nemitz, E., and Fowler, D.: Development of resistance models to describe measurements of bi-directional ammonia surface-atmosphere exchange, International Conference on Atmospheric Ammonia - Emissions, Deposition and Environmental Impacts, Culham, England, ISI:000072633600029, 473-480, 1995.

Taipale, R., Ruuskanen, T. M., Rinne, J., Kajos, M. K., Hakola, H., Pohja, T., and Kulmala, M.: Technical Note: Quantitative long-term measurements of VOC concentrations by PTR-MS measurement, calibration, and volume mixing ratio calculation methods, Atmos. Chem. Phys., 8, 6681-6698, doi:10.5194/acp8-6681-2008, 2008.

Tani, A., Hayward, S., and Hewitt, C. N.: Measurement of monoterpenes and related compounds by proton transfer reaction-mass spectrometry (PTR-MS), Int. J. Mass Spectrom., 223, 561-578, 2003.

Tani, A., Hayward, S., Hansel, A., and Hewitt, C. N.: Effect of water vapour pressure on monoterpene measurements using proton transfer reaction-mass spectrometry (PTR-MS), Int. J. Mass Spectrom., 239, 161-169, 2004.

Taraborrelli, D., Lawrence, M. G., Butler, T. M., Sander, R., and Lelieveld, J.: Mainz Isoprene Mechanism 2 (MIM2): an isoprene oxidation mechanism for regional and global atmospheric modelling, Atmos. Chem. Phys., 9, 2751-2777, doi:10.5194/acp-92751-2009, 2009.

Tatsuka, K., Suekane, S., Sakai, Y., and Sumitani, H.: Volatile constituents of kiwi fruit flowers - simultaneous distillation and extraction versus headspace sampling, J. Agr. Food Chem., 38, 2176-2180, 1990.

Tie, X., Guenther, A., and Holland, E.: Biogenic methanol and its impacts on tropospheric oxidants, Geophys. Res. Lett, 30, doi:10.1029/2003g1017167, 2003.

Warneke, C., Luxembourg, S. L., de Gouw, J. A., Rinne, H. J. I., Guenther, A. B., and Fall, R.: Disjunct eddy covariance measurements of oxygenated volatile organic compounds fluxes from an alfalfa field before and after cutting, J. Geophys. Res.-Atmos., 107(D8), doi:10.1029/2001JD000594, 2002.

White, M. L., Russo, R. S., Zhou, Y., Ambrose, J. L., Haase, K., Frinak, E. K., Varner, R. K., Wingenter, O. W., Mao, H., Talbot, R., and Sive, B. C.: Are biogenic emissions a significant source of summertime atmospheric toluene in the rural Northeastern United States?, Atmos. Chem. Phys., 9, 81-92, doi:10.5194/acp9-81-2009, 2009.

Wilkinson, M. J.: Circadian control of isoprene emissions from oil palm (Elaeis guineensis), PhD thesis, University of Lancaster, Lancaster, UK, 2005.

Wilkinson, M. J., Owen, S. M., Possell, M., Hartwell, J., Gould, P., Hall, A., Vickers, C., and Hewitt, C. N.: Circadian control of iso- 
prene emissions from oil palm (Elaeis guineensis), Plant Journal, 47, 960-968, doi:10.1111/j.1365-313X.2006.02847.x, 2006.

Winters, A. J., Adams, M. A., Bleby, T. M., Rennenberg, H., Steigner, D., Steinbrecher, R., and Kreuzwieser, J.: Emissions of isoprene, monoterpene and short-chained carbonyl compounds from Eucalyptus spp. in southern Australia, Atmos. Environ., 43, 3035-3043, doi:10.1016/j.atmosenv.2009.03.026, 2009. 